\title{
AN INTEGRATED INVENTORY MODEL WITH CAPACITY CONSTRAINT UNDER ORDER-SIZE DEPENDENT TRADE CREDIT, ALL-UNIT DISCOUNT AND PARTIAL BACKORDERING
}

\author{
Mukunda Choudhury, Chandan Mahato and Gour Chandra Mahata*
}

\begin{abstract}
In today's competitive business situation, the supplier frequently offers his or her retailers a permissible delay period (i.e., trade credit) to stimulate sales. In addition, the capacity of any warehouse is limited in practice, thus the retailer needs an additional rented warehouse (RW) to store the excess units when the order quantity exceeds the capacity of the own warehouse (OW). Furthermore, with the globalization of the marketing policy, the supplier may provide the retailer with a discounted price if the quantity of purchase is large enough. Considering all of the factors mentioned above, in this paper we study an integrated inventory model with capacity constraint under order-size dependent trade credit and all-units discount. Shortages are allowed and partially backordered. In addition, the unit production cost, which is a function of the production rate, is considered. An algorithm is developed to determine the optimal production and replenishment policies for both the supplier and the retailer. Finally, numerical examples are presented to illustrate theoretical results. Sensitivity analysis of the major parameters are performed and some insights are obtained.
\end{abstract}

Mathematics Subject Classification. 90B05.

Received March 11, 2021. Accepted February 5, 2022.

\section{INTRODUCTION}

Recently, with the emergence of market globalization, supply chain (SC) management and control have become a strategic focus of leading manufacturing companies. The ultimate objective of effective supply chain management is the reduction of costs, improvement of cash flow, and increased operational efficiency across the entire business through connecting inventory control, purchasing coordination, and sales order processing with market demand. In a competitive business environment, the ability to integrate one's supply chain is essential for company success. Each partner of SC is indented to increase his/her business sharing; consequently, they adopt tactics that help in it. Trade credit policy is one such a tactic. According to an estimate, more than $80 \%$ of business-to-business (B2B) transactions in the United Kingdom (UK), and about $80 \%$ of United States (US) firms offer their product on trade credit [27]. More recently, Seifert et al. further studied a sample of 3383 groups of public US firms and concluded that company profitability is positively associated with payment delay. Such

Keywords. Inventory, integrated model, order-size dependent trade credit, partial backordering, all-units discount, EOQ, capacity constraint.

Department of Mathematics, Sidho-Kanho-Birsha University, Purulia Sainik School, Purulia 723104, West Bengal, India.

*Corresponding author: gcmahata@yahoo.in, gourmahata@yahoo.co.in 
a worldwide practice encourages researchers to model the trade credit or permissible delay in payment while developing the mathematical models.

Goyal [9] was the first to study the EOQ model under the condition of permissible delay in payment. Later, Aggarwal and Jaggi [1] extended Goyal's model to consider the deterministic inventory model with a constant deterioration rate. Jamal et al. [12] further extended Aggarwal and Jaggi's model to allow for shortages, which makes the inventory model more applicable in practice. Ouyang et al. [23] expanded the model proposed by Goyal to consider deteriorating items and partially permissible delays in payment associated with order quantity. Yang et al. [34] investigated how the retailer determines the optimal ordering and payment policies when the supplier offers cash discounts or delayed payments depending on the order quantity. Recently, Lashgari et al. [19] investigated an inventory control problem for deteriorating items with two-level trade credit linked to order quantity. Related articles include studies by Sana [25], Khanra et al. [14], Sarkar [26], Jaggi et al. [11], Khanra et al. [15], Ray [24], Khanra et al. [16] and their references. All the inventory models above assume that the length of the trade credit period is a fixed value and independent of the retailer's order quantity.

However, in practice, some suppliers usually provide the retailer with a trade period depending on the retailer's order quantity to stimulate the size of orders and benefit from the economies of scale in purchasing, manufacturing, and transportation. There is also, another kind of contract in which the suppliers offer shorter credit periods or partial trade credit for a smaller quantity of orders and provide the retailers with a greater delay period for more than a certain volume.

In this regard, Khouja and Mehrez [18] investigated the effect of different payment policies including trade credit contracts on the optimal order quantity when the credit terms are linked to the quantity of orders. Under order quantity-dependent trade credit and price-linked demand, Shinn and Hwang [30] formulated the retailer's mathematical EOQ model to acquire its optimal order size and price. Chang et al. [3] established an EOQ model with deteriorating items where the supplier offers trade credit to the retailer only if the order quantity is greater than or equal to a specified threshold. Ouyang et al. [23] formulated an integrated inventory model of a supplier and a buyer when demand is price sensitive and the credit period offered by the supplier depends on the buyer's order size. Chiu et al. [6] formulated an integrated inventory model of a manufacturer and a buyer with order-size dependent trade credit and imperfect quality products. Huang [10] extended the model of Chang et al. [3] to consider partial trade credit if the order quantity is lower than a specific quantity. Ouyang et al. [22] proposed an EOQ model for deteriorating items under partially permissible delay in payments to be linked with order quantity as well. Other related studies including Chung et al. [7,8], Chen et al. [5], Ting [32], Shah et al. [28] and Tiwari et al. [33]. Clearly, there are two short comings in order-size dependent trade credit terms schedule based on the only one order quantity threshold: (1) The supplier needs fully grasp all kinds of information of the retailer (including market demand information, warehouse capacity information, cost structure information, etc.) to set an appropriate order quantity threshold. (2) For the retailer, the trade credit period with a single order quantity threshold forces the retailer to make two extreme choices: to enjoy a delay in payment by making the order quantity greater than or equal to the predetermined quantity, or to pay the full purchase amount immediately when the order quantity is less than the predetermined quantity. In the above-mentioned studies, the trade credit period is provided based on only one predefined order quantity. But this credit period based on one fixed order quantity consists of some drawbacks. For instance, in order to enjoy the delay payment policy according to a single fixed order quantity compels the retailer to make the order size greater than or equal to the fixed order quantity whatever the capacity of the warehouse of the retailer. On the other hand, it is really difficult to define the predefined fixed order quantity for the suppliers considering the different market demands of different retailers, and different capacities of the warehouses of different retailers. Therefore, to remove these drawbacks, it is necessary to develop a more flexible trade credit policy with different credit periods according to different fixed order quantities. Therefore, in order to reduce the difficulty of the supplier decision-making and meanwhile increase the retailer's choice, more flexible trade credit terms based on different trade credit periods and different quantities thresholds emerge. However, to the best of our knowledge, only a few researchers have paid attention to this kind of trade credit terms so far except Ouyang et al. [21] and Chang et al. [4]. Additionally, a discount facility on the unit purchase cost is another effective strategy 
for the supplier to allure the retailer for enlarging order size. This discount facility offers a lower purchase cost per unit for a sufficiently large enough order size. Consequently, to manipulate the opportunity of discounts on the unit purchase cost, a higher trade credit period, the retailer wants to enlarge the order amount with alacrity. In this case, a question may arise: Does the warehouse of the retailer always have sufficient capacity to hold the entire purchased amount? In this circumstance, an additional RW is required to hold the surplus purchased amounts than the capacity of OW. Moreover, shortages may appear and some customers may wait for backorders to be fulfilled while some may turn to other places $[12,19]$. Therefore, with more adaptation to the real world, this study would introduce a flexible trade credit policy and discount on unit purchase cost based on different quantity breaks interconnected with shortages and capacity constraints of the retailer's warehouse in the development of a specific inventory model.

Clearly, when the length of the trade credit period is linked to the order quantity rather than a given parameter, the retailer is encouraged to order more products to enjoy a longer trade credit period. But if the retailer's own warehouse $(\mathrm{OW})$ capacity is insufficient to store all the purchased units, the retailer needs a rented warehouse (RW) to store the excess units. Consequently, the assumption of a single warehouse in the classical EOQ model is no longer valid. The development of the two-warehouse inventory model will be more in line with the real business environment.

Also, in today's competitive global market, the supplier frequently offers the retailer a discounted price if the purchased quantity is large enough. Several types of single-item quantity discount approaches are used in practice and have been discussed in the literature, among which all-units discount is most widely used in the practical business environment. Specific literature on all-units discounts, we recommend that readers refer to the literature of Taleizadeh et al. [31], Alfares et al. [2] and Shaikh et al. [29]. In addition, to illustrate the contribution of this study, a comparison between this study and previous studies in Table 1.

From Table 1, it is clearly seen that no inventory model in the supply chain developed in previous studies has simultaneously considered capacity constraint, order-size dependent trade credit, all-units discount and partial backordering. Combining these factors, this paper derives a single-supplier, single-retailer integrated inventory model that considers the following features. (1) The retailer's OW capacity is limited, which means if the retailer's order quantity surpasses his/her OW capacity, an additional RW is needed to store the excess units; (2) the retailer receives an order-size dependent trade credit and an all-units discount from the supplier that also depends on the order size; (3) shortages are allowed and partial backordering. Hence, in the present paper, we have generalized many existing literatures, such as Goyal [9], Taleizadeh et al. [31] and Ouyang et al. [23], etc. Next, we proved the existence of the optimal solution of the objective function and then the closed-form optimal solution was found. After that, we designed an algorithm to find the global optimal solution of the problem in an integrated manner. Finally, some numerical examples are presented to illustrate theoretical results and managerial insights are given.

\section{NotATiOn AND ASSUMPTIONS}

The following notations and assumptions are used in formulating the model.

\subsection{Notation}

$A_{r} \quad$ Retailer's ordering cost per order

$A_{s} \quad$ Supplier's setup cost per setup

$D \quad$ Retailer's demand rate

$F_{0} \quad$ Fixed transportation cost per shipment

$F_{1} \quad$ Unit transportation cost

$R \quad$ Supplier's production rate, $(>D)$

$h_{r} \quad$ The stock holding cost per unit time in RW

$h_{o} \quad$ The stock holding cost per unit per unit time in OW

$h_{s} \quad$ Supplier's holding cost rate, excluding interest charged 
$c(R)$ Supplier's unit production cost which is a convex function of $R$

$c_{j} \quad$ Retailer's unit purchase cost for price range $j$

$p \quad$ Retailer's unit selling price

$\rho \quad$ Supplier's capacity utilization fraction i.e., $\rho=\frac{D}{R}$

$W \quad$ Maximum storage capacity of OW

$N \quad$ The retailer's trade credit period offered by the suppliers

$I_{S p} \quad$ Supplier's capital opportunity cost per dollar per unit time

$I_{R c} \quad$ Retailer's capital opportunity cost per dollar per unit time

$I_{R e} \quad$ Retailer's interest earned per dollar per unit time

$Q \quad$ Retailer's order quantity

$T \quad$ Retailer's replenishment cycle

$m \quad$ Number of shipments from the supplier to the retailer

$M \quad$ Number of shipments from the supplier to the retailer per production run, a positive integer

$K \quad$ Percentage of duration of period in which inventory level is positive

$\beta \quad$ Proportion of shortage that will be backordered

$C_{g} \quad$ The cost of goodwill loss for a unit of lost sale

$C_{b} \quad$ The backordering cost per unit per time due to shortages

$\pi_{j} \quad$ Lost sales cost per unit for price range $j$, including the lost profit and the goodwill loss

TABLE 1. Summarized and comparison of previous studies and this study.

\begin{tabular}{|c|c|c|c|c|c|c|}
\hline Author(s) & $\begin{array}{l}\text { Trade credit } \\
\text { policy }\end{array}$ & Shortages & $\begin{array}{l}\text { Storage } \\
\text { facilities }\end{array}$ & $\begin{array}{l}\text { Purchase } \\
\text { cost }\end{array}$ & $\begin{array}{l}\text { Solution } \\
\text { method }\end{array}$ & $\begin{array}{l}\text { Supply } \\
\text { chain type }\end{array}$ \\
\hline Goyal [9] & $\begin{array}{l}\text { Fixed trade } \\
\text { credit }\end{array}$ & No & $\begin{array}{l}\text { Single } \\
\text { warehouse }\end{array}$ & Constant & Closed-form & One level \\
\hline $\begin{array}{l}\text { Jamal } \\
\text { et al. }[12]\end{array}$ & $\begin{array}{l}\text { Fixed trade } \\
\text { credit }\end{array}$ & $\begin{array}{l}\text { Completely } \\
\text { backordering }\end{array}$ & $\begin{array}{l}\text { Single } \\
\text { warehouse }\end{array}$ & Constant & $\begin{array}{l}\text { Non-closed } \\
\text { form }\end{array}$ & One level \\
\hline $\begin{array}{l}\text { Yang et al. } \\
{[34]}\end{array}$ & $\begin{array}{l}\text { Fixed trade } \\
\text { credit }\end{array}$ & $\begin{array}{l}\text { Partial backo- } \\
\text { rdering }\end{array}$ & $\begin{array}{l}\text { Two ware- } \\
\text { houses }\end{array}$ & Constant & $\begin{array}{l}\text { Non-closed } \\
\text { form }\end{array}$ & One level \\
\hline $\begin{array}{l}\text { Jaggi et al. } \\
{[11]}\end{array}$ & $\begin{array}{l}\text { Fixed trade } \\
\text { credit }\end{array}$ & $\begin{array}{l}\text { Completely } \\
\text { backordering }\end{array}$ & $\begin{array}{l}\text { Two ware- } \\
\text { houses }\end{array}$ & Constant & $\begin{array}{l}\text { Non-closed } \\
\text { form }\end{array}$ & One level \\
\hline $\begin{array}{l}\text { Chen et al. } \\
{[16]}\end{array}$ & $\begin{array}{l}\text { Conditional } \\
\text { trade credit }\end{array}$ & No & $\begin{array}{l}\text { Single } \\
\text { warehouse }\end{array}$ & Constant & Closed-form & One level \\
\hline $\begin{array}{l}\text { Taleizadeh } \\
\text { et al. }[31]\end{array}$ & No & $\begin{array}{l}\text { Partial backo- } \\
\text { rdering }\end{array}$ & $\begin{array}{l}\text { Single } \\
\text { warehouse }\end{array}$ & $\begin{array}{l}\text { Linked to } \\
\text { order }\end{array}$ & Closed-form & One level \\
\hline $\begin{array}{l}\text { Ouyang } \\
\text { et al. }[23]\end{array}$ & $\begin{array}{l}\text { Order-size } \\
\text { dependent } \\
\text { trade credit }\end{array}$ & No & $\begin{array}{l}\text { Two ware- } \\
\text { houses }\end{array}$ & Constant & Closed-form & One level \\
\hline $\begin{array}{l}\text { Chang } \\
\text { et al. [4] }\end{array}$ & $\begin{array}{l}\text { Order-size } \\
\text { dependent } \\
\text { trade credit }\end{array}$ & No & $\begin{array}{l}\text { Single } \\
\text { warehouse }\end{array}$ & Constant & $\begin{array}{l}\text { Non-closed } \\
\text { form }\end{array}$ & One level \\
\hline $\begin{array}{l}\text { Alfares } \\
\text { et al. [2] }\end{array}$ & No & No & $\begin{array}{l}\text { Single } \\
\text { warehouse }\end{array}$ & $\begin{array}{l}\text { Linked to } \\
\text { order }\end{array}$ & Closed-form & One level \\
\hline $\begin{array}{l}\text { Lashgari } \\
\text { et al. [19] }\end{array}$ & $\begin{array}{l}\text { Fixed trade } \\
\text { credit }\end{array}$ & $\begin{array}{l}\text { Partial backo- } \\
\text { rdering }\end{array}$ & $\begin{array}{l}\text { Single } \\
\text { warehouse }\end{array}$ & Constant & Closed-form & One level \\
\hline $\begin{array}{l}\text { Shaikh } \\
\text { et al. [29] }\end{array}$ & No & $\begin{array}{l}\text { Partial backo- } \\
\text { rdering }\end{array}$ & $\begin{array}{l}\text { Single } \\
\text { warehouse }\end{array}$ & $\begin{array}{l}\text { Linked to } \\
\text { order }\end{array}$ & $\begin{array}{l}\text { Non-closed } \\
\text { form }\end{array}$ & One level \\
\hline $\begin{array}{l}\text { This } \\
\text { paper }\end{array}$ & $\begin{array}{l}\text { Order-size } \\
\text { dependent } \\
\text { trade credit }\end{array}$ & $\begin{array}{l}\text { Partial backo- } \\
\text { rdering }\end{array}$ & $\begin{array}{l}\text { Two ware- } \\
\text { houses }\end{array}$ & $\begin{array}{l}\text { Linked to } \\
\text { order }\end{array}$ & Closed-form & Two level \\
\hline
\end{tabular}




\subsection{Assumptions}

(1) There are a single retailer and a single supplier in the inventory system. The retailer orders $Q$ units in each order. The supplier manufactures $m Q$ units in each production run to reduce the setup cost and delivers $Q$ units to the retailer in each shipment.

(2) The unit production cost $c(R)$ is a convex function of the production rate $R$, and is given by $c(R)=$ $c_{0 p}+\frac{c_{1 p}}{R}+c_{2 p} R$, where $c_{0 p}, c_{1 p}$ and $c_{2 p}$ are non-negative real numbers. The fixed cost $c_{0 p}$ can be regarded as the material cost. The cost component $\frac{c_{1 p}}{R}$ decreases as the production rate increases, representing costs such as labor cost or energy cost. The third term $c_{2 p} R$ denotes a cost component that increases with the production rate such as an additional tool or die wear at high production rate. For notational simplicity, $c(R)$ and $c$ are used interchangeably in this paper. (This assumption has been used by Khouja [17], Ouyang et al. [20] and others).

(3) Lead time is zero and replenishment rate is infinite.

(4) Demand rate is known and constant.

(5) Shortages are allowed and partially backordered, and the fraction of shortages is backordered at a constant rate $\beta$.

(6) The OW has a limited capacity of $W$ units. When $Q>W$, the retailer needs to rent an additional warehouse to hold the excess units. In addition, we assume that the RW has an unlimited capacity. Moreover, in practice, the RW usually offers better preserving facilities than the OW, thus this paper uses the relationship $h_{r} \geq h_{o}$ to reflect this situation. Moreover, the products in RW are consumed first to reduce the retailer's holding cost.

(7) In actual commercial operations, the larger the retailer's order quantity, the lower the purchase price. Here we assume that the supplier offers an all-units quantity discount to the retailer. The purchase cost is a decreasing step function of the order size $Q$ :

$$
c=\left\{\begin{array}{cc}
c_{1}, & \eta_{1} \leq Q \leq \eta_{2} \\
c_{2}, & \eta_{2} \leq Q \leq \eta_{3} \\
\vdots & \vdots \\
c_{\lambda}, & \eta_{\lambda} \leq Q \leq \eta_{\lambda+1}
\end{array}\right.
$$

where $1=\eta_{1}<\eta_{2}<\ldots<\eta_{\lambda}<\eta_{\lambda+1}=\infty$, each of which represents a boundary quantity. $c_{\varepsilon}$ denotes the unit purchase cost applicable to orders whose lot size $Q$ falls in the interval $c_{1}>c_{2}>\ldots>c_{\lambda}$.

(8) The supplier offers a credit period $N_{m}, m=1,2, \ldots, \mu$, which is also related to the retailer's order quantity and the relationship is given as follows:

$$
N=\left\{\begin{array}{cc}
N_{1} & \vartheta_{1} \leq Q \leq \vartheta_{2} \\
N_{2} & \vartheta_{2} \leq Q \leq \vartheta_{3} \\
\vdots & \vdots \\
N_{\mu} & \vartheta_{\mu} \leq Q \leq \vartheta_{\mu+1}
\end{array}\right.
$$

where $1=\vartheta_{1}<\vartheta_{2}<\ldots<\vartheta_{\mu}<\vartheta_{\mu+1}=\infty$, each of which is a boundary values at which a specific credit period is offered. $N_{m}$ denotes the credit period applicable to orders whose lot size $Q$ falls in the interval $\vartheta_{m}$ to $\vartheta_{m+1}$ with $N_{1}<N_{2}<\ldots<N_{\mu}$.

(9) From assumptions (3.7) and (3.8), the retailer is presented with an order-size dependent trade-credit schedule and an all-units quantity discounts schedule. For convenience, we now combine the two discount schedules into a restructured new discount schedule. Rearrange boundary values $\eta_{1}, \eta_{2}, \ldots, \eta_{\lambda}$ and $\vartheta_{1}, \vartheta_{2}, \ldots, \vartheta_{\mu}$ in the order of small to large to form a new set of $q_{1}<q_{2}<\ldots, q_{k}$. Then there only exists a unique combination of purchase cost $c_{j}$ and credit period $M_{j}$ applicable to the lot size falling in the interval $q_{j}$ to $q_{j+1}$. The restructured discount schedule becomes 


\begin{tabular}{|c|c|c|c|}
\hline$j$ & $Q$ & $c$ & $M$ \\
\hline 1 & $q_{1}=1 \leq Q<q_{2}$ & $c_{1}$ & $M_{1}$ \\
2 & $q_{2} \leq Q<q_{3}$ & $c_{2}$ & $M_{2}$ \\
$\vdots$ & $\vdots$ & $\vdots$ & $\vdots$ \\
$k$ & $q_{k} \leq Q<q_{k+1}$ & $c_{k}$ & $M_{k}$ \\
\hline
\end{tabular}

where $k \leq \lambda+\mu, 1=q_{1}<q_{2}<\ldots<q_{k}<q_{k+1}=\infty$. For $q_{j} \leq Q \leq q_{j+1}, j=1,2, \ldots, k$, the purchase cost and the length of credit period offered by supplier are $c_{j}$ and $M_{j}$ respectively, where $c_{1}>c_{2}>\ldots>c_{k}>0$ and $0<M_{1}<M_{2}<\ldots<M_{k}$.

(10) During the credit period, the account is not settled, the retailer sells the items and uses the sales revenues to earn interest at a rate of $I_{R e}$. At the end of the credit period, the retailer pays off all units bought, and starts to pay for the interest charges on the items remaining in stock with at a rate of $I_{R c}$.

(11) By offering trade credit to the retailer, the supplier bears opportunity cost at the rate of $I_{S p}$ for the offered credit period.

\section{Model formulation}

In this section, we first establish the total profit functions for the supplier and the retailer respectively, and then make some appropriate combination to obtain the supplier-retailer integrated total profit function.

\subsection{Supplier's total profit per unit time}

The supplier produces a batch quantity of $m Q$ units in each production run; hence, the production cycle length for the supplier is $\frac{m Q}{D}=m T$. The supplier's total profit per unit time is the total sales revenue minus the total relevant cost (which consists of the production cost, setup cost, inventory holding cost and opportunity cost for offering trade credit). These components are evaluated as follows:

(a) Sales revenue: the sales revenue per unit time is given by $c_{j} D[K+(1-K) \beta]$.

(b) Production cost: the production cost per unit time is given by $c D[K+(1-K) \beta]$.

(c) Setup cost: the supplier manufactures $m Q$ in one production run. The cycle length is $m Q / D=m T$. Therefore, the setup cost per unit time is $A_{s} /(m T)$.

(d) Holding cost: the supplier's inventory per cycle can be calculated by subtracting the retailer's accumulated inventory level from the supplier's accumulated inventory level. Hence, the supplier's average inventory per unit time is given by

$$
\begin{aligned}
\frac{\left\{m Q\left[\frac{Q}{R}+(m-1) \frac{Q}{D}\right]-\frac{m^{2} Q^{2}}{2 R}-\frac{Q^{2}}{D}[1+2+\ldots+(m-1)]\right\}}{\frac{m Q}{D}} & =\frac{Q}{2 R}[(m-1)(R-D)+D] \\
& =\frac{D T}{2}[(m-1)(1-\rho)+\rho],
\end{aligned}
$$

where $\rho=\frac{D}{R}$.

Considering the inventory holding cost, it can be split into two components: real holding cost and opportunity holding cost. The first component relates to the actual ownership of the goods and includes such items as storage and maintenance, which are accounted for on a per-unit-of-inventory basis. The second component is the capital locked with the inventory. On other words, the opportunity holding cost is charged on the money value of the inventory on hand. Because the production cost per unit is $c$, the holding cost rate excluding interest charges is $h_{s}$, hence the real holding cost per unit per unit time is $c \times h_{s}$. Also, the supplier's capital opportunity cost per dollar per unit time is $I_{S p}$, we can get the opportunity holding cost per unit per unit time as $c \times I_{S p}$.

Therefore, the supplier's holding cost per unit time is $c\left(h_{s}+I_{S p}\right) D T[(m-1)(1-\rho)+\rho] / 2$. 
Note that a similar derivation in the supplier's average inventory using a manufacturing lot size of $m Q$ units can be found in Joglekar [13].

(e) Opportunity cost: offering a credit period $M_{i}$ to the retailer, the opportunity cost per unit time is $c_{j} I_{S p} m Q M_{j} /(m T)=c_{j} I_{S p} D[K+(1-K) \beta] M_{j}$.

Consequently, when the supplier provides a given credit period $M_{j}, j=1,2, \ldots, k$ to the retailer, the total profit per unit time (denoted by $\operatorname{STP}_{j}(m)$ ) is a function of $m$ and can be expressed as

$$
\begin{aligned}
\operatorname{STP}_{j}(m, K)= & \text { sales revenue }- \text { production cost }- \text { setup cost }- \text { holding cost }- \text { opportunity cost } \\
= & \left(c_{j}-c\right) D[K+(1-K) \beta]-\frac{A_{s}}{m T}-\frac{c\left(h_{s}+I_{S p}\right) D T[(m-1)(1-\rho)+\rho]}{2} \\
& -c_{j} I_{S p} D[K+(1-K) \beta] M_{j} .
\end{aligned}
$$

\subsection{Retailer's total profit per unit time}

Suppose the retailer's order size of the product, without loss of generality, is $\in\left[q_{j}, q_{j+1}\right)$ for the entire cycle length $T$. In accordance with the assumptions, the purchase cost offered by supplier is $c_{j}$ and the length of the credit period is $M_{j}$ for the purchase cost. The retailer receives the products at the starting time $t=0$ of the inventory system and the stock level remains positive during the time interval $[0, K T]$ after fulfilling the customer's demand. Shortly after, shortages are allowed and partially backlogged with a constant rate $\beta$ during time interval $[K T, T]$. Therefore, the retailer's order size for the cycle length $T$ is $Q=K T D+(1-K) \beta D T$. The duration for consuming the maximum storage capacity, $W$, of the retailer OW is obtained as: $T_{W}=W / D$. Based on the assumptions, if the remaining number of products of the retailer's total ordered quantities after fulfilling the backorders $K D T$ exceeds the capacity of the OW, i.e., $W$, then the retailer needs a rented warehouse to keep the excess amount.

As to the retailer, the annual total profit is composed of sales revenue, ordering cost, purchasing cost, holding cost, back ordering cost, opportunity cost due to lost sales, interest charged and the interest earned. Now the identical terms of the components of the retailer's net profit per unit of time are computed as follows:

Annual sales revenue: $p D[K+(1-K) \beta]$.

Annual ordering cost: $A_{r} / T$.

Annual purchasing cost: $c_{j} D[K+(1-K) \beta]$.

Annual transportation cost: $\left(F_{0}+F_{1} Q\right) / T=\frac{F_{0}}{T}+F_{1} D[K+(1-K) \beta]$.

Annual holding cost: if the retailer's order quantity $Q \leq W$ (i.e., $T \leq T_{w}$ ), the retailer keeps all the products in his/her OW. Otherwise, the retailer keeps the excess amount than $W$, i.e., $K D T-W$ in a rented warehouse (RW). Thus, holding cost per unit per unit of time is computed as follows:

$$
\left\{\begin{array}{l}
\frac{h_{0} D K^{2} T}{2} T \leq T_{w} \\
\frac{h_{r}(K D T-W)^{2}}{2 D T}+\frac{h_{0}(2 D K T-W) W}{2 D T} T \geq T_{w} .
\end{array}\right.
$$

Annual backordering cost: $\frac{c_{b} \beta D(1-k)^{2} T}{2}$.

Annual opportunity cost due to lost sales: $c_{g} D(1-K)(1-\beta)$.

The non-identical terms of the components of the retailer's net profit per unit of time are interest charged per unit time and interest earned per unit time due to the credit period facilities from the supplier to the retailer. There are two possibilities for the interest earned and interest charged according to the values of duration of the positive inventory level $K T$ and allowed trade credit period $M_{j}$. The possible situations are: situation 1: $K T \leq M_{j}$ and situation 2: $K T \geq M_{j}$, which are depicted in Figure 1. We will discuss them separately.

Situation 1: $K T \leq M_{j}(j=1,2, \ldots k)$ 


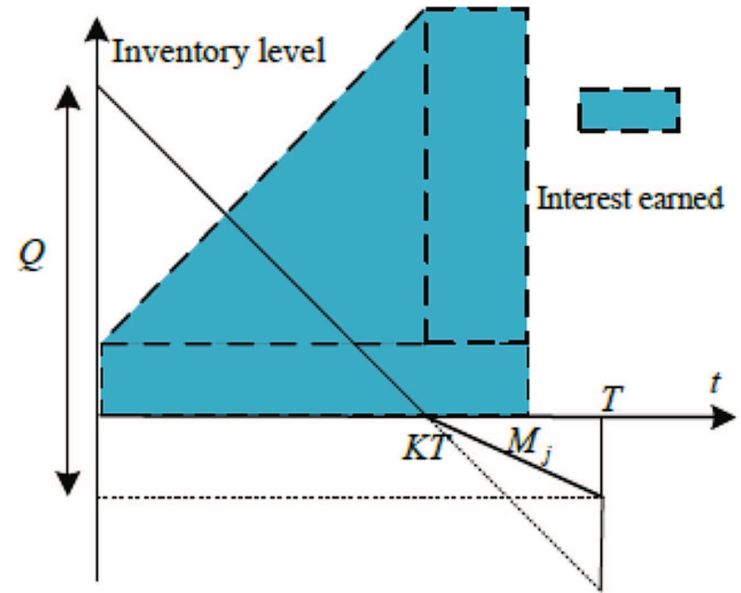

(a)

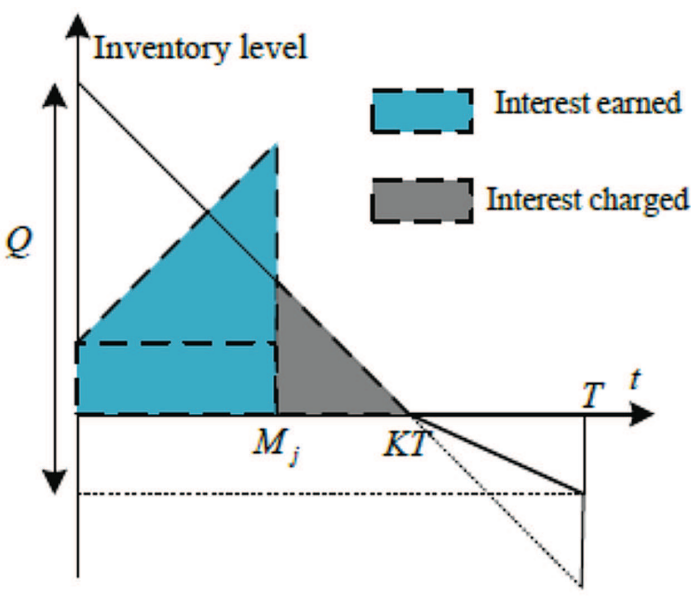

(b)

FiguRE 1. Interest charged and interest earned under various situations. (a) $K T \leq M_{j}$. (b) $K T \geq M_{j}$.

In this situation, the retailer's trade credit period $M_{j}$ is longer than or equal to the positive inventory level length $K T$ (see Fig. 1a). It indicates that the retailer has sold all the stock at the time $M_{j}$. Therefore, there is no interest charged. On the other hand, the retailer's interest earned per cycle contains two parts: (1) during the period $[0, K T]$, the retailer can obtain the interest earned on the sales revenue received (including sale revenues from backlogged); and (2) the retailer can use all the sales revenue to earn interest during the period, $\left[K T, M_{j}\right]$. Therefore, the annual total interest earned is

$$
\frac{\left[p I_{R e} \int_{0}^{K T} D t \mathrm{~d} t+p I_{R e} D K T\left(M_{j}-K T\right)+p I_{R e}(1-K) \beta D T M_{j}\right]}{T}=p I_{R e} D\left[K\left(M_{j}-\frac{K T}{2}\right)+(1-K) \beta M_{j}\right] .
$$

Situation 2: $K T \geq M_{j}(j=1,2, \ldots k)$

In this situation, the retailer's delay payment period $M_{j}$ is shorter than or equal to the positive inventory level length $K T$ (see Fig. 1b), it indicates that the retailer has some inventory available after due date $M_{j}$. Thus, during the period $\left[M_{j}, K T\right]$, the retailer must pay the interest for the items in stock, then the annual total interest charged is

$$
\frac{\left[c_{j} I_{R c} \int_{M_{j}}^{K T} D(K T-t) \mathrm{d} t\right]}{T}=\frac{c_{j} I_{R c} D\left(K T-M_{j}\right)^{2}}{2 T} .
$$

Also, during the period $\left[0, M_{j}\right]$, the retailer can use the sales revenue to gain interest. Hence, the annual total interest earned is

$$
\frac{\left[p I_{R e} \int_{0}^{M_{j}} D t \mathrm{~d} t+p I_{R e}(1-K) \beta D T M_{j}\right]}{T}=p I_{R e} D\left[\frac{M_{j}^{2}}{2 T}+(1-K) \beta M_{j}\right] .
$$

Combining the above results, for given $M_{j}, j=1,2, \ldots, k$, and based on the length of $K T$ and $T_{w}$, the retailer's annual profit function under various situations can be expressed as 
$\operatorname{ATP}_{i}^{(j)}(K, T)(i=1,2)=$ annual sales revenue - annual ordering cost - annual purchasing cost - annual transportation cost - annual holding cost - annual backordering cost - annual opportunity cost due to lost sales - annual interest charged + annual interest earned.

$$
\begin{aligned}
& \operatorname{ATP}_{1}^{(j)}(K, T)= \begin{cases}\operatorname{ATP}_{11}^{(j)}(K, T), & M_{j} \leq K T \leq T_{w} \\
\operatorname{ATP}_{12}^{(j)}(K, T), & 0<K T \leq T_{w} \leq M_{j} \text { or } 0<K T \leq M_{j} \leq T_{w}\end{cases} \\
& \operatorname{ATP}_{2}^{(j)}(K, T)= \begin{cases}\operatorname{ATP}_{21}^{(j)}(K, T), & T_{w} \leq M_{j} \leq K T \text { or } M_{j} \leq T_{w} \leq K T \\
\operatorname{ATP}_{22}^{(j)}(K, T), & T_{w} \leq K T \leq M_{j}\end{cases}
\end{aligned}
$$

where,

$$
\begin{aligned}
\operatorname{ATP}_{11}^{(j)}(K, T)= & p D[K+(1-K) \beta]-\frac{A_{r}}{T}-c_{j} D[K+(1-K) \beta]-\left(\frac{F_{0}}{T}+F_{1} D[K+(1-K) \beta]\right) \\
& -\frac{h_{0} D K^{2} T}{2}-\frac{c_{b} \beta D(1-k)^{2} T}{2}-c_{g} D(1-K)(1-\beta)-\frac{c_{j} I_{R c} D\left(K T-M_{j}\right)^{2}}{2 T} \\
& +p I_{R e} D\left[\frac{M_{j}^{2}}{2 T}+(1-K) \beta M_{j}\right] \\
\operatorname{ATP}_{12}^{(j)}(K, T)= & p D[K+(1-K) \beta]-\frac{A_{r}}{T}-c_{j} D[K+(1-K) \beta]-\left(\frac{F_{0}}{T}+F_{1} D[K+(1-K) \beta]\right) \\
& -\frac{h_{0} D K^{2} T}{2}-\frac{c_{b} \beta D(1-k)^{2} T}{2}-c_{g} D(1-K)(1-\beta) \\
& +p I_{R e} D\left[K\left(M_{j}-\frac{K T}{2}\right)+(1-K) \beta M_{j}\right] \\
\operatorname{ATP}_{21}^{(j)}(K, T)= & p D[K+(1-K) \beta]-\frac{A_{r}}{T}-c_{j} D[K+(1-K) \beta]-\left(\frac{F_{0}}{T}+F_{1} D[K+(1-K) \beta]\right) \\
& -\frac{h_{r}(K D T-W)^{2}}{2 D T}-\frac{h_{0}(2 D K T-W) W}{2 D T}-\frac{c_{b} \beta D(1-k)^{2} T}{2}-c_{g} D(1-K)(1-\beta) \\
& -\frac{c_{j} I_{R c} D\left(K T-M_{j}\right)^{2}}{2 T}+p I_{R e} D\left[\frac{M_{j}^{2}}{2 T}+(1-K) \beta M_{j}\right] \\
& +p I_{R e} D\left[K\left(M_{j}-\frac{K T}{2}\right)+(1-K) \beta M_{j}\right] . \\
& -\frac{h_{r}(K D T-W)^{2}}{2 D T}-\frac{h_{0}(2 D K T-W) W}{2 D T}-\frac{c_{b} \beta D(1-k)^{2} T}{2}-c_{g} D(1-K)(1-\beta) \\
\operatorname{ATP}_{22}^{(j)}(K, T)= & p[K+(1-K) \beta]-\frac{A_{r}}{T}-c_{j} D[K+(1-K) \beta]-\left(\frac{F_{0}}{T}+F_{1} D[K+(1-K) \beta]\right)
\end{aligned}
$$

Here, equation (3.6) represents the retailer's annual profit function when he or she does not need to rent an additional warehouse (i.e., $K T \leq T_{w}$ ). More specifically, for $M_{j} \leq K T \leq T_{w}$, it indicates that the retailer needs to use equations (3.4) and (3.5) to calculate interest charged and interest earned, and the holding cost is referred to equation (3.2a). Therefore, the retailer's annual profit function in this case can be described as equation (3.7). For $0<K T \leq T_{w} \leq M_{j}$ or $0<K T \leq M_{j} \leq T_{w}$, it indicates that there is no interest charged and the retailer needs to use equation (3.2) to calculate interest earned, and the holding cost is referred to equation (3.2a). Therefore, the retailer's annual profit function in this case can be described as equation (3.9).

Similarly, equation (3.7) represents the retailer's annual profit function when he or she need to rent an additional warehouse (i.e., $K T \geq T_{w}$ ). For $T_{w} \leq M_{j} \leq K T$ or $M_{j} \leq T_{w} \leq K T$, it indicates that the retailer 
needs to use equations (3.4) and (3.5) to calculate interest charged and interest earned, and the holding cost is referred to equation (3.2b). Therefore, the retailer's annual profit function in this case can be described as equation (3.10). For $T_{w} \leq K T \leq M_{j}$, it indicates that there is no interest charged and the retailer needs to use equation (3.3) to calculate interest earned, and the holding cost is referred to equation ( $3.2 \mathrm{~b})$. Therefore, the retailer's annual profit function in this case can be described as equation (3.11).

\subsection{The integrated total profit function}

Once the supplier and retailer have established a long-term strategic partnership and are treated as an integrated supply chain system and decide to share resources with each other to undertake mutually beneficial cooperation, the joint total profit per unit time can be obtained as the sum of the supplier's and the retailer's total profit per unit time and is a function of $m, K$, and $T$ as follows:

$$
\begin{gathered}
\operatorname{JTP}^{(j)}(m, K, T)=\left\{\begin{array}{l}
\operatorname{JTP}_{1}^{(j)}(m, K, T) \\
\operatorname{JTP}_{2}^{(j)}(m, K, T)
\end{array}\right. \\
=\left\{\begin{array}{l}
\operatorname{ATP}_{1}^{(j)}+\mathrm{STP}_{j}= \begin{cases}\operatorname{JTP}_{11}^{(j)}(m, K, T)=\operatorname{ATP}_{11}^{(j)}(K, T)+\operatorname{STP}_{j}(m, K), & M_{j} \leq K T \leq T_{w} \\
\operatorname{JTP}_{12}^{(j)}(m, K, T)=\operatorname{ATP}_{12}^{(j)}(K, T)+\operatorname{STP}_{j}(m, K), & 0<K T \leq T_{w} \leq M_{j} \text { or } \\
\operatorname{JTP}_{21}^{(j)}(m, K, T)=\operatorname{ATP}_{21}^{(j)}(K, T)+\operatorname{STP}_{j}(m, K), & 0<K T \leq M_{w} \leq T_{w} \leq M_{j} \leq K T \text { or }\end{cases} \\
\operatorname{ATP}_{2}^{(j)}+\operatorname{STP}_{j}= \begin{cases}M_{j} \leq T_{w} \leq K T \\
\operatorname{JTP}_{22}^{(j)}(m, K, T)=\operatorname{ATP}_{22}^{(j)}(K, T)+\operatorname{STP}_{j}(m, K), & T_{w} \leq K T \leq M_{j}\end{cases}
\end{array}\right.
\end{gathered}
$$

where

$$
\begin{aligned}
\operatorname{JTP}_{11}^{(j)}(m, K, T)= & p D[K+(1-K) \beta]-\frac{A_{r}}{T}-c_{j} D[K+(1-K) \beta]-\left(\frac{F_{0}}{T}+F_{1} D[K+(1-K) \beta]\right) \\
& -\frac{h_{0} D K^{2} T}{2}-\frac{c_{b} \beta D(1-k)^{2} T}{2}-c_{g} D(1-K)(1-\beta)-\frac{c_{j} I_{R c} D\left(K T-M_{j}\right)^{2}}{2 T} \\
& +p I_{R e} D\left[\frac{M_{j}^{2}}{2 T}+(1-K) \beta M_{j}\right]+\left(c_{j}-c\right) D[K+(1-K) \beta]-\frac{A_{s}}{m T} \\
& -\frac{c\left(h_{s}+I_{S p}\right) D T[(m-1)(1-\rho)+\rho]}{2}-c_{j} I_{S p} D[K+(1-K) \beta] M_{j} \\
\operatorname{JTP}_{12}^{(j)}(m, K, T)= & p D[K+(1-K) \beta]-\frac{A_{r}}{T}-c_{j} D[K+(1-K) \beta]-\left(\frac{F_{0}}{T}+F_{1} D[K+(1-K) \beta]\right) \\
& -\frac{h_{0} D K^{2} T}{2}-\frac{c_{b} \beta D(1-k)^{2} T}{2}-c_{g} D(1-K)(1-\beta) \\
& +p I_{R e} D\left[K\left(M_{j}-\frac{K T}{2}\right)+(1-K) \beta M_{j}\right]+\left(c_{j}-c\right) D[K+(1-K) \beta]-\frac{A_{s}}{m T} \\
& -\frac{c\left(h_{s}+I_{S p}\right) D T[(m-1)(1-\rho)+\rho]}{2}-c_{j} I_{S p} D[K+(1-K) \beta] M_{j} \\
& p D[K+(1-K) \beta]-\frac{A_{r}}{T}-c_{j} D[K+(1-K) \beta]-\left(\frac{F_{0}}{T}+F_{1} D[K+(1-K) \beta]\right) \\
& -\frac{h_{r}(K D T-W)^{2}}{2 D T}-\frac{h_{0}(2 D K T-W) W}{2 D T}-\frac{c_{b} \beta D(1-k)^{2} T}{2}-c_{g} D(1-K)(1-\beta) \\
& -\frac{c_{j} I_{R c} D\left(K T-M_{j}\right)^{2}}{2 T}+p I_{R e} D\left[\frac{M_{j}^{2}}{2 T}+(1-K) \beta M_{j}\right]+\left(c_{j}-c\right) D[K+(1-K) \beta]-\frac{A_{s}}{m T} \\
\operatorname{JTP}_{21}^{(j)}(m, K, T) &
\end{aligned}
$$




$$
\begin{aligned}
& -\frac{c\left(h_{s}+I_{S p}\right) D T[(m-1)(1-\rho)+\rho]}{2}-c_{j} I_{S p} D[K+(1-K) \beta] M_{j} \\
\mathrm{JTP}_{22}^{(j)}(m, K, T)= & p D[K+(1-K) \beta]-\frac{A_{r}}{T}-c_{j} D[K+(1-K) \beta]-\left(\frac{F_{0}}{T}+F_{1} D[K+(1-K) \beta]\right) \\
& -\frac{h_{r}(K D T-W)^{2}}{2 D T}-\frac{h_{0}(2 D K T-W) W}{2 D T}-\frac{c_{b} \beta D(1-k)^{2} T}{2}-c_{g} D(1-K)(1-\beta) \\
& +p I_{R e} D\left[K\left(M_{j}-\frac{K T}{2}\right)+(1-K) \beta M_{j}\right]+\left(c_{j}-c\right) D[K+(1-K) \beta]-\frac{A_{s}}{m T} \\
& -\frac{c\left(h_{s}+I_{S p}\right) D T[(m-1)(1-\rho)+\rho]}{2}-c_{j} I_{S p} D[K+(1-K) \beta] M_{j} .
\end{aligned}
$$

\section{Theoretical Results}

In this section, the closed form optimal solutions for the decision variables are formulated to maximize the joint total profit function per unit time in (3.13)-(3.16) by the similar fashion which is presented in Lashgari et al. [19]. Now the closed form solutions for each case are derived as follows:

Firstly, for fixed $M_{j}, j=1,2, \ldots, k$, and any given $(K, T)$, we temporarily relax the integer requirement on $m$ and take the second partial derivative of $\operatorname{JTP}_{i}^{(j)}(m, K, T), i=1,2$ with respect to $m$ which gives

$$
\frac{\partial^{2} \operatorname{JTP}_{i}^{(j)}(m, K, T)}{\partial m^{2}}=\frac{\partial^{2} \mathrm{JTP}_{i k}^{(j)}(m, K, T)}{\partial m^{2}}=\frac{-2 A_{s}}{m^{3} T}<0, \quad i, k=1,2 .
$$

It is obvious from equation (4.1) that for any given $(K, T), \operatorname{JTP}_{i}^{(j)}(m, K, T)$ is a concave function in $m$, where $i=1,2$ for any given $(K, T)$. Hence, searching for the optimal solution of shipment number $m$ is reduced to find a local optimal solution.

Next, for fixed $m$, we will discuss how to find the optimal solution $(K, T)$. There are four casesarising as follows:

(i) $M_{j} \leq K T \leq T_{w}$,

(ii) $0<K T \leq T_{w} \leq M_{j}$ or $0<K T \leq M_{j} \leq T_{w}$,

(iii) $T_{w} \leq M_{j} \leq K T$ or $M_{j} \leq T_{w} \leq K T$, and

(iv) $T_{w} \leq K T \leq M_{j}$.

\subsection{Case 1-1: $M_{j} \leq K T \leq T_{w}$}

Maximizing equation (3.13) is equivalent to minimizing the following function

$$
\operatorname{JTP}_{11}^{(j)}(m, K, T)=\varphi_{111} K^{2} T-\varphi_{112} K T-\varphi_{113} K+\varphi_{114} T+\frac{\varphi_{115}}{T}+\varphi_{116}
$$

where $\varphi_{111}, \varphi_{112}, \varphi_{113}, \varphi_{114}, \varphi_{115}$, and $\varphi_{115}$ are given in Appendix A.

First, for any given $K$, take the first and second derivatives of $\operatorname{JTP}_{11}^{(j)}(m, K, T)$ with respect to $T$, we obtain equations (4.3) and (4.4), respectively

$$
\begin{aligned}
\frac{\partial \operatorname{JTP}_{11}^{(j)}(m, K, T)}{\partial T} & =K^{2} \varphi_{111}-K \varphi_{112}+\varphi_{114}-\frac{\varphi_{115}}{T^{2}} \\
\frac{\partial^{2} \operatorname{JTP}_{11}^{(j)}(m, K, T)}{\partial T^{2}} & =\frac{2 \varphi_{115}}{T^{3}} .
\end{aligned}
$$

From equation (4.4), if $\varphi_{115}>0$, then $\frac{\partial^{2} \mathrm{JTP}_{11}^{(j)}(m, K, T)}{\partial T^{2}}>0$, i.e., $\operatorname{JTP}_{11}^{(j)}(m, K, T)$ is strictly convex function of $T$. Setting $\frac{\partial \operatorname{JTP}_{11}^{(j)}(m, K, T)}{\partial T}=0$ yields 


$$
T=\sqrt{\frac{\varphi_{115}}{\psi_{11}(m, K)}}
$$

where, $\psi_{11}(m, K)=K^{2} \varphi_{111}-K \varphi_{112}+\varphi_{114}$.

The discriminant of $\psi_{11}(m, K)$,

$$
\Delta=\varphi_{112}^{2}-4 \varphi_{111} \varphi_{114}=-D^{2}\left[c_{b} \beta\left(h_{0}+c_{j} I_{R c}\right)+\left(h_{0}+c_{b} \beta+c_{j} I_{R c}\right) c\left(h_{s}+I_{S p}\right)\{(m-1)(1-\rho)+\rho\}\right]<0,
$$

is always negative. Thus $\psi_{11}(m, K)$ has no roots and it is always either negative or positive. Since $\psi_{11}(m, 0)=$ $\varphi_{114}=\frac{D}{2}\left[c_{b} \beta+c\left(h_{s}+I_{S p}\right)\{(m-1)(1-\rho)+\rho\}\right]>0$, we can conclude that $\psi_{11}(m, K)$ is strictly positive in $[0,1]$. So, equation $(4.12)$ is feasible, and for all $K \in[0,1]$, there is always a unique $T=\sqrt{\frac{\varphi_{115}}{\psi_{11}(m, K)}}$ such that minimizes $\operatorname{JTP}_{11}^{(j)}(m, K, T)$.

Substituting equation (4.4) into equation (4.2) (i.e., $T=\sqrt{\frac{\varphi_{115}}{\psi_{11}(m, K)}}$ into $\left.\operatorname{JTP}_{11}^{(j)}(m, K, T)\right)$ leads to

$$
\operatorname{JTP}_{11}^{(j)}(m, K)=2 \sqrt{\varphi_{115} \psi_{11}(m, K)}-\varphi_{113} K+\varphi_{116} .
$$

Taking the first and second derivatives of equation (4.6) with respect to $K$, we have

$$
\begin{aligned}
\mathrm{JTP}_{11}^{\prime(j)}(m, K) & =\sqrt{\varphi_{115}}\left(\frac{\psi_{11}^{\prime}(m, K)}{\sqrt{\psi_{11}(m, K)}}\right)-\varphi_{113}=\sqrt{\varphi_{115}}\left(\frac{2 \psi_{11}(m, K)_{11}^{\prime \prime}(m, K)-\left(\psi_{11}^{\prime}(m, K)\right)^{2}}{2\left(\psi_{11}(m, K)\right)^{\frac{3}{2}}}\right) \\
& =\sqrt{\varphi_{115}}\left(\frac{4 \varphi_{111}\left(K^{2} \varphi_{111}-K \varphi_{112}+\varphi_{114}\right)-\left(2 K \varphi_{111}-\varphi_{112}\right)^{2}}{2\left(\psi_{11}(m, K)\right)^{\frac{3}{2}}}\right) \\
& =\sqrt{\varphi_{115}}\left(\frac{4 \varphi_{111} \varphi_{114}-\varphi_{112}^{2}}{2\left(\psi_{11}(m, K)\right)^{\frac{3}{2}}}\right) \\
& =\frac{\sqrt{\varphi_{115}} D^{2}\left[c_{b} \beta\left(h_{0}+c_{j} I_{R c}\right)+\left(h_{0}+c_{b} \beta+c_{j} I_{R c}\right) c\left(h_{s}+I_{S p}\right)\{(m-1)(1-\rho)+\rho\}\right]}{2\left(\psi_{11}(m, K)\right)^{\frac{3}{2}}}>0 .
\end{aligned}
$$

From equation (4.7), $\operatorname{JTP}_{11}^{(j)}(m, K)$ is a strictly convex function of $K$. We check that

$$
\operatorname{JTP}_{11}^{\prime(j)}(m, 0)=-\varphi_{112} \sqrt{\frac{\varphi_{115}}{\varphi_{114}}}-\varphi_{113}
$$

Note that if $\operatorname{JTP}_{11}^{\prime(j)}(m, 0) \geq 0$, then $\operatorname{JTP}_{11}^{(j)}(m, K)$ is increasing on [0,1], i.e., $\operatorname{JTP}_{11}^{(j)}(m, K)$ reaches the global minimum at $K=0$, and it indicates that the best choice is that retailers do not build inventory. Therefore, we only need to consider the situation of $\operatorname{JTP}_{11}^{\prime(j)}(m, 0)<0$. We further investigate

$$
\begin{aligned}
\operatorname{JTP}_{11}^{\prime(j)}(m, 1)= & \sqrt{\varphi_{115}}\left(\frac{2 \varphi_{111}-\varphi_{112}}{\sqrt{\varphi_{111}-\varphi_{112}+\varphi_{114}}}\right)-\varphi_{113} \\
= & \sqrt{A_{r}+F_{0}+\frac{A_{s}}{m}+\frac{\left(c_{j} I_{R c}-p I_{R e}\right) D M_{j}^{2}}{2}}\left(\frac{\sqrt{2 D}\left(h_{0}+c_{j} I_{R c}\right)}{\sqrt{h_{0}+c_{j} I_{R c}+c\left(h_{s}+I_{S p}\right)\{(m-1)(1-\rho)+\rho\}}}\right) \\
& -\left[\left(p-F_{1}+c_{g}-c\right) D(1-\beta)-c_{j} I_{S p} M_{j} D(1-\beta)+\left(c_{j} I_{R c}-p \beta I_{R e}\right) D M_{j}\right] .
\end{aligned}
$$

From equation (4.8), $\operatorname{JTP}_{11}^{\prime(j)}(m, 1)>0$ hold if and only if 


$$
\begin{aligned}
& \left(p-F_{1}+c_{g}-c\right) D-c_{j} I_{S p} M_{j} D+c_{j} I_{R c} M_{j} D-\sqrt{2 A_{r}+2 F_{0}+\frac{2 A_{s}}{m}+\left(c_{j} I_{R c}-p I_{R e}\right) D M_{j}^{2}} \\
& \beta>\frac{\sqrt{D}\left(h_{0}+c_{j} I_{R c}\right)}{\left(\frac{c^{h_{0}+c_{j} I_{R c}+c\left(h_{s}+I_{S p}\right)\{(m-1)(1-\rho)+\rho\}}}{(m)}\right)} \\
& =\beta_{11} . \\
& \left(p-F_{1}+c_{g}-c\right) D-c_{j} I_{S p} M_{j} D+p I_{R e} M_{j} D
\end{aligned}
$$

Thus, if the inequality in equation (4.10) is established, $\operatorname{JTP}_{11}^{(j)}(m, K)$ has a unique minimizer in the open interval $(0,1)$, and the global optimum values of $T_{11}$ and $K_{11}$ can be obtained using equations (4.11) and (4.12), respectively (see Appendix B, Eqs. (B.3) and (B.4)). Otherwise, the global minimizer will lie on the boundary point $K_{11}=1$ (see Appendix C)

$$
\begin{aligned}
T_{11} & =\sqrt{\frac{4 \varphi_{111} \varphi_{115}-\varphi_{113}^{2}}{4 \varphi_{111} \varphi_{114}-\varphi_{112}^{2}}} \\
K_{11} & =\frac{\varphi_{112}}{2 \varphi_{111}}+\frac{\varphi_{113}}{2 \varphi_{111}} \sqrt{\frac{4 \varphi_{111} \varphi_{114}-\varphi_{112}^{2}}{4 \varphi_{111} \varphi_{115}-\varphi_{113}^{2}}} .
\end{aligned}
$$

Here, for the discriminant term $\beta_{11}$, it should be be noted that,

(1) if $0 \leq \beta_{11} \leq \beta$, the optimal is that the retailer uses partial backlogging, and the optimal values of $T_{11}$ and $K_{11}$ can be obtained using equations (4.11) and (4.12) respectively.

(2) If $0<\beta<\beta_{11}$, the optimal is that the retailer employs inventory policy with without shortages (e.g., $\left.K_{11}=1\right)$

(3) If $\beta_{11}<0$, the retailer need to compare the cases of no stocking (e.g., $\left.K_{11}=0\right)$ and partial backlogging to determine which is optimal.

In addition, for the solutions $K_{11}$ and $T_{11}$ found by using equations (4.11) and (4.12), if the condition $M_{j} \leq K_{11} T_{11} \leq T_{w}$ is not satisfied, it implies that $\operatorname{JTP}_{11}^{(j)}(m, K, T)$ will obtain the optimal solution at the boundary. A logical solution is to set $T=\frac{M_{j}}{K_{11}}$ or $T=\frac{T_{w}}{K_{11}}$, then we recommend that readers refer to the detailed solution process given in Appendix D.

To sum up, based on the above analysis, the order quantity for trade credit period $M_{j}$ and purchase cost $c_{j}$ can be computed form equation (4.13), namely,

$$
Q_{j}=D T[K+(1-K) \beta] .
$$

From equation (4.13), if the optimal order quantity $\left(Q_{j}\right)$ satisfies $q_{j} \leq Q_{j}<q_{j+1}$, the solution obtained by the analysis above is feasible. Otherwise, we need to use the solution procedure given in Appendix D to determine the optimal values of $T$ and $K$.

Case 1-2: $0<K T \leq T_{w} \leq M_{j}$ or $0<K T \leq M_{j} \leq T_{w}$

Similar to Case 1-1, maximizing equation (3.14) is equivalent to minimizing the following function

$$
\operatorname{JTP}_{12}^{(j)}(m, K, T)=\varphi_{121} K^{2} T-\varphi_{122} K T-\varphi_{123} K+\varphi_{124} T+\frac{\varphi_{125}}{T}+\varphi_{126}
$$

where $\varphi_{121}, \varphi_{122}, \varphi_{123}, \varphi_{124}, \varphi_{125}$, and $\varphi_{126}$ are given in Appendix A.

Note that equations (4.14) and (4.2) have similar function structures (i.e., $\varphi_{121}$ through $\varphi_{126}$ instead of $\varphi_{111}$ through $\left.\varphi_{116}\right)$. So, the analysis and discussion provided for equations (4.3)-(4.8) of Case 1-1 is also established for Case 1-2. Next, the equivalent analysis for Case 1-2 of equation (4.9) for Case 1-1 is

$$
\operatorname{JTP}_{12}^{\prime(j)}(m, 1)=\sqrt{\varphi_{125}}\left(\frac{2 \varphi_{121}-\varphi_{122}}{\sqrt{\varphi_{121}-\varphi_{122}+\varphi_{124}}}\right)-\varphi_{123}
$$




$$
\begin{aligned}
= & \sqrt{A_{r}+F_{0}+\frac{A_{s}}{m}}\left(\frac{\sqrt{2 D}\left(h_{0}+p I_{R e}\right)}{\sqrt{h_{0}+p I_{R e}+c\left(h_{s}+I_{S p}\right)\{(m-1)(1-\rho)+\rho\}}}\right) \\
& -\left[\left(p-F_{1}+c_{g}-c\right) D(1-\beta)+\left(p I_{R e}-c_{j} I_{S p}\right) D M_{j}(1-\beta)\right] .
\end{aligned}
$$

From equation (4.15), $\operatorname{JTP}_{12}^{\prime(j)}(m, 1)>0$ hold if and only if

$$
\begin{aligned}
\beta & >\frac{\left(p-F_{1}+c_{g}-c\right) D+\left(p I_{R e}-c_{j} I_{S p}\right) D M_{j}-\sqrt{A_{r}+F_{0}+\frac{A_{s}}{m}}\left(\frac{\sqrt{2 D}\left(h_{0}+p I_{R e}\right)}{\sqrt{h_{0}+p I_{R e}+c\left(h_{s}+I_{S p}\right)\{(m-1)(1-\rho)+\rho\}}}\right)}{\left(p-F_{1}+c_{g}-c\right) D+\left(p I_{R e}-c_{j} I_{S p}\right) D M_{j}} \\
& =\beta_{12} .
\end{aligned}
$$

Consequently, if the inequality in equation (4.16) is established, $\operatorname{JTP}_{12}^{(j)}(m, K)$ has a uniqueminimizer in the open interval $(0,1)$, and the global optimum values of $T_{12}$ and $K_{12}$ can be obtained using equations (4.17) and (4.18), respectively (see Appendix B). Otherwise, the global minimizer will lie on the boundary point $K_{12}=1$ (see Appendix C).

$$
\begin{aligned}
T_{12} & =\sqrt{\frac{4 \varphi_{121} \varphi_{125}-\varphi_{123}^{2}}{4 \varphi_{121} \varphi_{124}-\varphi_{122}^{2}}} \\
K_{12} & =\frac{\varphi_{122}}{2 \varphi_{121}}+\frac{\varphi_{123}}{2 \varphi_{121}} \sqrt{\frac{4 \varphi_{121} \varphi_{124}-\varphi_{122}^{2}}{4 \varphi_{121} \varphi_{125}-\varphi_{123}^{2}}} .
\end{aligned}
$$

Similar to Case 1-1, we still need to perform the following two steps to ensure the feasibility of the solution:

(1) For the solutions $K_{12}$ and $T_{12}$ found by using equations (4.17) and (4.18), check whether they satisfy $K_{12} T_{12} \leq \min \left\{M_{j}, T_{w}\right\}$ and if not, we need to use Appendix D to determine the optimal values of $T$ and $K$.

(2) Check whether the order quantity $Q_{j}$ satisfies $q_{j} \leq Q_{j}<q_{j+1}$, and if not, we need to use Appendix D to determine the optimal values of $T$ and $K$.

\section{Case 2-1: $T_{w} \leq M_{j} \leq K T$ or $M_{j} \leq T_{w} \leq K T$}

Similarly, maximizing equations (3.15) is equivalent to minimizing the following function

$$
\mathrm{JTP}_{21}^{(j)}(m, K, T)=\varphi_{211} K^{2} T-\varphi_{212} K T-\varphi_{213} K+\varphi_{214} T+\frac{\varphi_{215}}{T}+\varphi_{216}
$$

where $\varphi_{211}, \varphi_{212}, \varphi_{213}, \varphi_{214}, \varphi_{215}$, and $\varphi_{216}$ are given in Appendix A.

Similar to previous cases,

$$
\begin{aligned}
\operatorname{JTP}_{21}^{(j)}(m, 1)= & \sqrt{\varphi_{215}}\left(\frac{2 \varphi_{211}-\varphi_{212}}{\sqrt{\varphi_{211}-\varphi_{212}+\varphi_{214}}}\right)-\varphi_{213} \\
= & \sqrt{A_{r}+F_{0}+\frac{A_{s}}{m}+\frac{\left(c_{j} I_{R c}-p I_{R e}\right) D M_{j}^{2}}{2}+\frac{\left(h_{r}-h_{0}\right) W^{2}}{2 D}} \\
& \times\left(\frac{\sqrt{2 D}\left(h_{r}+c_{j} I_{R c}\right)}{\sqrt{h_{r}+c_{j} I_{R c}+c\left(h_{s}+I_{S p}\right)\{(m-1)(1-\rho)+\rho\}}}\right) \\
& -\left[\left(p-F_{1}+c_{g}-c\right) D(1-\beta)+\left(h_{r}-h_{0}\right) w-c_{j} I_{S p} M_{j} D(1-\beta)+\left(c_{j} I_{R c}-p \beta I_{R e}\right) D M_{j}\right] .
\end{aligned}
$$

From equation (4.20), $\operatorname{JTP}_{21}^{\prime(j)}(m, 1)>0$ hold if and only if 


$$
\begin{aligned}
& \beta>\frac{\left(p-F_{1}+c_{g}-c\right) D+c_{j}\left(I_{R c}-I_{S p}\right) M_{j} D+\left(h_{r}-h_{0}\right) W}{-\sqrt{2 A_{r}+2 F_{0}+\frac{2 A_{s}}{m}+\left(c_{j} I_{R c}-p I_{R e}\right) D M_{j}^{2}+\frac{\left(h_{r}-h_{0}\right) W^{2}}{D}}\left(\frac{\sqrt{D}\left(h_{r}+c_{j} I_{R c}\right)}{\sqrt{h_{r}+c_{j} I_{R c}+c\left(h_{s}+I_{S p}\right)\{(m-1)(1-\rho)+\rho\}}}\right)} \\
& =\beta_{21} .
\end{aligned}
$$

Consequently, if the inequality in equation (4.21) is established, $\operatorname{JTP}_{21}^{(j)}(m, K)$ has a unique minimizer in the open interval $(0,1)$, and the global optimum values of $T_{21}$ and $K_{21}$ can be obtained using equations (4.22) and (4.23), respectively (see Appendix B). Otherwise, the global minimizer will lie on the boundary point $K_{21}=1$. (see Appendix C)

$$
\begin{aligned}
T_{21} & =\sqrt{\frac{4 \varphi_{211} \varphi_{215}-\varphi_{213}^{2}}{4 \varphi_{211} \varphi_{214}-\varphi_{212}^{2}}} \\
K_{21} & =\frac{\varphi_{212}}{2 \varphi_{211}}+\frac{\varphi_{213}}{2 \varphi_{211}} \sqrt{\frac{4 \varphi_{211} \varphi_{214}-\varphi_{212}^{2}}{4 \varphi_{211} \varphi_{215}-\varphi_{213}^{2}}} .
\end{aligned}
$$

Similar to previous cases, the feasibility of the solution needs to be checked. If the solution is not feasible, we suggest that readers refer to the detailed solution process given in Appendices D and E.

\section{Case 2-2: $T_{w} \leq K T \leq M_{j}$}

Similarly, maximizing equation (3.16) is equivalent to minimizing the following function

$$
\mathrm{JTP}_{22}^{(j)}(m, K, T)=\varphi_{221} K^{2} T-\varphi_{222} K T-\varphi_{223} K+\varphi_{224} T+\frac{\varphi_{225}}{T}+\varphi_{226}
$$

where, $\varphi_{221}, \varphi_{222}, \varphi_{223}, \varphi_{224}, \varphi_{225}$, and $\varphi_{226}$ are given in Appendix A.

Similarly,

$$
\begin{aligned}
\operatorname{JTP}_{22}^{\prime(j)}(m, 1)= & \sqrt{\varphi_{225}}\left(\frac{2 \varphi_{221}-\varphi_{222}}{\sqrt{\varphi_{221}-\varphi_{222}+\varphi_{224}}}\right)-\varphi_{223} \\
= & \sqrt{A_{r}+F_{0}+\frac{A_{s}}{m}+\frac{\left(h_{r}-h_{0}\right) W^{2}}{2 D}}\left(\frac{\sqrt{2 D}\left(h_{r}+p I_{R e}\right)}{\sqrt{h_{r}+p I_{R e}+c\left(h_{s}+I_{S p}\right)\{(m-1)(1-\rho)+\rho\}}}\right) \\
& -\left[\left(p-F_{1}+c_{g}-c\right) D(1-\beta)+\left(h_{r}-h_{0}\right) w+\left(p I_{R e}-c_{j} I_{S p}\right) D M_{j}(1-\beta)\right] .
\end{aligned}
$$

From equation (4.25), $\operatorname{JTP}_{22}^{\prime(j)}(m, 1)>0$ hold if and only if

$$
\begin{aligned}
& \left(p-F_{1}+c_{g}-c\right) D+\left(p I_{R e}-c_{j} I_{S p}\right) D M_{j}+\left(h_{r}-h_{0}\right) W-\sqrt{2 A_{r}+2 F_{0}+\frac{2 A_{s}}{m}+\frac{\left(h_{r}-h_{0}\right) W^{2}}{D}} \\
& \beta>\frac{\left(\frac{\sqrt{D}\left(h_{r}+p I_{R e}\right)}{\sqrt{h_{r}+p I_{R e}+c\left(h_{s}+I_{S p}\right)\{(m-1)(1-\rho)+\rho\}}}\right)}{\left(p-F_{1}+c_{g}-c\right) D+\left(p I_{R e}-c_{j} I_{S p}\right) D M_{j}} \\
& =\beta_{22} .
\end{aligned}
$$

Consequently, if the inequality in equation (4.26) is established, $\operatorname{JTP}_{22}^{(j)}(m, K)$ has a unique minimizer in the open interval $(0,1)$, and the global optimum values of $T_{22}$ and $K_{22}$ can be obtained using equations (4.27) and (4.28), respectively (see Appendix B). Otherwise, the global minimizer will lie on the boundary point $K_{21}=1$ (see Appendix C).

$$
T_{22}=\sqrt{\frac{4 \varphi_{221} \varphi_{225}-\varphi_{223}^{2}}{4 \varphi_{221} \varphi_{224}-\varphi_{222}^{2}}}
$$


TABLE 2. Optimal solution, when $T$ and $K$ do not satisfy the condition.

\begin{tabular}{|c|c|c|}
\hline Cases & Possibility & Optimal solution \\
\hline \multirow[t]{2}{*}{ Case 1-1 } & $T_{11}^{\prime}=\frac{M_{j}}{K_{11}^{\prime}}$ & $K_{11}^{\prime}=\sqrt{\frac{\varphi_{114} M_{j}^{2}}{M_{j}^{2} \varphi_{111}-M_{j} \varphi_{113}+\varphi_{115}}}$ \\
\hline & $\frac{K_{w}}{K_{11}}<T_{11}$ & $K_{11}^{\prime}=\sqrt{\frac{\varphi_{114} T_{w}^{2}}{T_{w}^{2} \varphi_{111}-T_{w} \varphi_{113}+\varphi_{115}}}$ \\
\hline Case 1-2 & $\frac{\min \left\{T_{w}, M_{j}\right\}}{K_{12}}<T_{12} \quad T_{12}^{\prime}=\frac{\min \left\{T_{w}, M_{j}\right\}}{K_{12}^{\prime}}$ & $T_{12}^{\prime}=\sqrt{\frac{\varphi_{124}\left(\min \left\{T_{w}, M_{j}\right\}\right)^{2}}{\left(\min \left\{T_{w}, M_{j}\right\}\right)^{2} \varphi_{121}-\min \left\{T_{w}, M_{j}\right\} \varphi_{123}+\varphi_{125}}}$ \\
\hline Case 2-1 & $\frac{\max \left\{T_{w}, M_{j}\right\}}{K_{21}}>T_{21} T_{21}^{\prime}=\frac{\max \left\{T_{w}, M_{j}\right\}}{K_{21}^{\prime}}$ & $K_{21}^{\prime}=\sqrt{\frac{\varphi_{214}\left(\max \left\{T_{w}, M_{j}\right\}\right)^{2}}{\left(\max \left\{T_{w}, M_{j}\right\}\right)^{2} \varphi_{211}-\max \left\{T_{w}, M_{j}\right\} \varphi_{213}+\varphi_{215}}}$ \\
\hline \multirow[t]{2}{*}{ Case 2-2 } & $\frac{M_{j}}{K_{22}}<T_{22}$ & $K_{22}^{\prime}=\sqrt{\frac{\varphi_{224} M_{j}^{2}}{M_{j}^{2} \varphi_{221}-M_{j} \varphi_{223}+\varphi_{225}}}$ \\
\hline & $\frac{K_{w}}{K_{22}}<T_{22}$ & $K_{22}^{\prime}=\sqrt{\frac{\varphi_{224} T_{w}^{2}}{T_{w}^{2} \varphi_{221}-T_{w} \varphi_{223}+\varphi_{225}}}$ \\
\hline
\end{tabular}

$$
K_{22}=\frac{\varphi_{222}}{2 \varphi_{221}}+\frac{\varphi_{223}}{2 \varphi_{221}} \sqrt{\frac{4 \varphi_{221} \varphi_{224}-\varphi_{222}^{2}}{4 \varphi_{221} \varphi_{225}-\varphi_{223}^{2}}} .
$$

Similarly, Appendices D and E are used to determine the optimal values of $T$ and $K$ if the solution is not feasible (Tab. 2).

Algorithm: summarizing the above results, we can establish the following algorithm to find the optimal solution $\left(m^{*}, K^{*}, T^{*}\right)$.

Algorithm 4.1. Step 1. Set $m=1$.

Step 2. For each $j, j=1,2, \ldots, k-1, k$, perform Steps $3-5$.

Step 3. Compare $M_{j}$ and $T_{w}$, if $M_{j}<T_{w}$, go to Step 4; if not, go to Step 5.

Step 4. Execute Steps 4.1-4.4, and determine $\left(K_{(j)}^{* *}, T_{(j)}^{* *}\right)$ and $\operatorname{JTP}^{(j)}\left(m, K_{(j)}^{* *}, T_{(j)}^{* *}\right)$.

Step 4.1. Determine $\left(K_{11}^{* *}, T_{11}^{* *}\right)$ and $\operatorname{JTP}_{11}^{(j)}\left(m, K_{11}^{* *}, T_{11}^{* *}\right)$ using Algorithm A provided in Appendix F, and go to Step 4.2 .

Step 4.2. Determine $\left(K_{12}^{* *}, T_{12}^{* *}\right)$ and $\operatorname{JTP}_{12}^{(j)}\left(m, K_{12}^{* *}, T_{12}^{* *}\right)$ using Algorithm B provided in Appendix G, and go to Step 4.3 .

Step 4.3. Determine $\left(K_{21}^{* *}, T_{21}^{* *}\right)$ and $\operatorname{JTP}_{21}^{(j)}\left(m, K_{21}^{* *}, T_{21}^{* *}\right)$ using Algorithm C provided in Appendix H, and go to Step 4.4.

Step 4.4. Set $\operatorname{JTP}^{(j)}\left(m, K_{(j)}^{* *}, T_{(j)}^{* *}\right)=\max \left\{\operatorname{JTP}_{11}^{(j)}\left(m, K_{11}^{* *}, T_{11}^{* *}\right), \operatorname{JTP}_{12}^{(j)}\left(m, K_{12}^{* *}, T_{12}^{* *}\right)\right.$, $\left.\mathrm{JTP}_{21}^{(j)}\left(m, K_{21}^{* *}, T_{21}^{* *}\right)\right\}$.

Step 5. Execute Steps 5.1-5.4, and determine $\left(K_{(j)}^{* *}, T_{(j)}^{* *}\right)$ and $\operatorname{JTP}^{(j)}\left(m, K_{(j)}^{* *}, T_{(j)}^{* *}\right)$.

Step 5.1. Determine $\left(K_{12}^{* *}, T_{12}^{* *}\right)$ and $\operatorname{JTP}_{12}^{(j)}\left(m, K_{12}^{* *}, T_{12}^{* *}\right)$ using Algorithm B provided in Appendix G, and go to Step 5.2. 
Step 5.2. Determine $\left(K_{21}^{* *}, T_{21}^{* *}\right)$ and $\operatorname{JTP}_{21}^{(j)}\left(m, K_{21}^{* *}, T_{21}^{* *}\right)$ using Algorithm C provided in Appendix H, and go to Step 5.3.

Step 5.3. Determine $\left(K_{22}^{* *}, T_{22}^{* *}\right)$ and $\operatorname{JTP}_{22}^{(j)}\left(m, K_{22}^{* *}, T_{22}^{* *}\right)$ using Algorithm D provided in Appendix I, and go to Step 5.4.

Step 5.4. Set $\operatorname{JTP}^{(j)}\left(m, K_{(j)}^{* *}, T_{(j)}^{* *}\right)=\max \left\{\operatorname{JTP}_{12}^{(j)}\left(m, K_{12}^{* *}, T_{12}^{* *}\right), \operatorname{JTP}_{21}^{(j)}\left(m, K_{21}^{* *}, T_{21}^{* *}\right)\right.$,

$$
\left.\operatorname{JTP}_{22}^{(j)}\left(m, K_{22}^{* *}, T_{22}^{* *}\right)\right\}
$$

Step 6. $\operatorname{Set} \operatorname{JTP}\left(m, K_{m}^{* *}, T_{m}^{* *}\right)=\max _{j=1,2, \ldots, k}\left\{\operatorname{JTP}^{(j)}\left(m, K_{(j)}^{* *}, T_{(j)}^{* *}\right)\right\}$.

Step 7. Set $m=m+1$, repeat Steps $2-6$ to find $\operatorname{JTP}\left(m, K_{m}^{* *}, T_{m}^{* *}\right)$.

Step 8. If $\operatorname{JTP}\left(m, K_{m}^{* *}, T_{m}^{* *}\right) \geq \operatorname{JTP}\left(m-1, K_{(m-1)}^{* *}, T_{(m-1)}^{* *}\right)$, go to Step 7. Otherwise, go to Step 9 .

Step 9. Set $\left(m^{*}, K^{* *}, T^{* *}\right)=\left(m-1, K_{(m-1)}^{* *}, T_{(m-1)}^{* *}\right) \cdot\left(m^{*}, K^{* *}, T^{* *}\right)$ is the optimal solution and $Q^{* *}=$ $D T^{* *}\left[\left(1-K^{* *}\right) \beta+K^{* *}\right]$.

\section{NumericAl EXAMPLES AND SENSITIVITY ANALYSIS}

In this section, some examples are provided to illustrate the theoretical results and solution procedure obtained in this paper. In addition, we also carry out a sensitivity analysis of major parameters.

Example 5.1. The input parameters are as follows: $A_{r}=\$ 100 /$ order, $A_{s}=\$ 180 /$ order, $D=350$ units/year, $F_{0}=\$ 50 /$ shipment, $F_{1}=\$ 0.2 /$ unit, $R=500$ units/year, $h_{r}=\$ 2 /$ unit/year, $h_{0}=\$ 1.4 /$ unit $/$ year, $h_{s}=$ $\$ 0.8 /$ unit/year, $c_{0 p}=\$ 2 /$ unit, $c_{1 p}=\$ 2.5 /$ unit, $c_{2 p}=\$ 0.5 /$ unit, $p=\$ 15 /$ unit, $W=150$ units (hence, $T_{W}=$ $150 / 350=0.429$ year) $I_{S p}=0.1, I_{R c}=0.10, I_{R e}=0.12, c_{g}=2, c_{b}=4, \beta=0.85$.

In addition, the supplier offers an all-units quantity discounts schedule, which is $c=\left(c_{1}, c_{2}, c_{3}\right)=$ $\$(10,9.7,9.4) /$ unit, $\eta=\left(\eta_{1}, \eta_{2}, \eta_{3}\right)=(1,150,500)$ unit, and the trade credit period schedule offered by the supplier is $N=\left(N_{1}, N_{2}, N_{3}\right)=(0.30,0.45,0.60)$ year, $\vartheta=\left(\vartheta_{1}, \vartheta_{2}, \vartheta_{3}\right)=(1,350,600)$ unit. Combining the two discount schedules above, we obtain a new schedule, namely, $(c, M)=$ $\left\{\left(c_{1}, M_{1}\right),\left(c_{2}, M_{2}\right),\left(c_{3}, M_{3}\right),\left(c_{4}, M_{4}\right),\left(c_{5}, M_{5}\right)\right\}=(\$$, year $)\{(10,0.30),(9.7,0.30),(9.7,0.45),(9.4,0.45),(9.4$, $0.60)\}, q=\left(q_{1}, q_{2}, q_{3}, q_{4}\right)=(1,150,350,500,600)$ unit.

Applying Algorithm 4.1, the solution procedure is shown in Table 3. As can be seen from Table 3, when $k=2$, the joint total annual profit is the largest, i.e., $\mathrm{JTP}^{*}=\mathrm{JTP}_{21}^{(2)}=\$ 4579.54$. Furthermore, the optimal solution is $m^{* *}=5, K^{* *}=K_{21}=0.9101, T^{* *}=T_{21}=0.4940$ year, the retailer's optimal order quantity is $Q^{* *}=Q_{21}=170.56$ units, the supplier's optimal production quantity is $m^{* *} Q^{* *}=852.8$ units. Meanwhile, the purchase price and trade credit chosen by the retailer is $c_{2}=9.7$ and $N_{1}=0.3$, respectively. Also, we notice that $W=150<157.36=0.9101 \times 0.4940 \times 350=K^{* *} T^{* *} D$, which means the capacity of OW is insufficient to store the ordered quantity, so an additional warehouse (RW) is necessary for the retailer.

Example 5.2. This example concerns the impact of the OW capacity and credit period on the optimal solution. The parameter values are identical to those used in Example 5.1 except for $W$ and $\left(N_{1}, N_{2}, N_{3}\right)$. Table 4 shows the optimal solutions for each value of $W=\{100,200,300,400,500\}$ and $\left(N_{1}, N_{2}, N_{3}\right)=$ $\{(0.10,0.20,0.30),(0.30,0.45,0.60),(0.40,0.60,0.80),(0.60,0.70,0.80)\}$.

Table 4 shows that when the OW capacity is relatively small (i.e., $W<200$ ), the retailer must rent a warehouse to enjoy a longer credit period and a lower purchase price. However, we notice that when the value of the credit period is relatively long (i.e., $\left(N_{1}, N_{2}, N_{3}\right)=\{(0.40,0.60,0.80)\}$, retailers typically orders larger quantities to benefit from a longer credit period, such that a rented warehouse is necessary. Moreover, the supplier's optimal shipment number decreases for longer credit periods, and the joint total profit per unit time increases with the increase the capacity of OW or the length of the credit. Based on the above results, we have several managerial implications. First, trade credit linked to the order quantity is an effective tool or means if 
TABLE 3. Solution procedure of Example 5.1.

\begin{tabular}{|c|c|c|c|c|c|c|}
\hline & Case & $m^{*}$ & $K^{*}$ & $T^{*}$ & $Q^{*}$ & JTP $^{*}$ \\
\hline 1 & $\begin{array}{l}\text { Case } 1-1 \\
\text { Case 1-2 } \\
\text { Case 2-1 }\end{array}$ & $\begin{array}{l}1 \\
1 \\
\times\end{array}$ & $\begin{array}{l}K_{11}=0 \\
K_{12}=0 \\
\times\end{array}$ & $\begin{array}{l}T_{11}=\mathrm{inf} \\
T_{12}=\mathrm{inf} \\
\times\end{array}$ & $\begin{array}{l}Q_{11}=0 \\
Q_{12}=0 \\
\times\end{array}$ & $\begin{array}{l}\mathrm{JTP}_{11}^{(1)}=-2450 \leftarrow \\
\operatorname{JTP}_{12}^{(1)}=-2450 \leftarrow \\
\times\end{array}$ \\
\hline 2 & $\begin{array}{l}\text { Case 1-1 } \\
\text { Case 1-2 } \\
\text { Case 2-1 }\end{array}$ & $\begin{array}{l}5 \\
5 \\
5\end{array}$ & $\begin{array}{l}K_{11}=0.9053 \\
K_{12}=0.4072 \\
K_{21}=0.9101\end{array}$ & $\begin{array}{l}T_{11}=0.4734 \\
T_{12}=0.7368 \\
T_{21}=0.4940\end{array}$ & $\begin{array}{l}Q_{11}=163.33 \\
Q_{12}=234.95 \\
Q_{21}=170.56\end{array}$ & $\begin{array}{l}\mathrm{JTP}_{11}^{(2)}=4579.06 \leftarrow \\
\mathrm{JTP}_{12}^{(2)}=4441.78 \leftarrow \\
\mathrm{JTP}_{21}^{(2)}=4579.54 \leftarrow^{a}\end{array}$ \\
\hline$\overline{3}$ & $\begin{array}{l}\text { Case 1-1 } \\
\text { Case 2-1 } \\
\text { Case 2-2 }\end{array}$ & $\begin{array}{l}\times \\
5 \\
\times \\
\end{array}$ & $\begin{array}{l}\times \\
K_{21}=0.7154 \\
\times\end{array}$ & $\begin{array}{l}\times \\
T_{21}=1.0446 \\
\times\end{array}$ & $\begin{array}{l}\times \\
Q_{21}=350 \\
\times\end{array}$ & $\begin{array}{l}\times \\
\operatorname{JTP}_{21}^{(3)}=4573.94 \leftarrow \\
\times\end{array}$ \\
\hline 4 & $\begin{array}{l}\text { Case } 1-1 \\
\text { Case 2-1 } \\
\text { Case } 2-2\end{array}$ & $\begin{array}{l}\times \\
5 \\
\times\end{array}$ & $\begin{array}{l}\times \\
K_{21}=0.6734 \\
\times\end{array}$ & $\begin{array}{l}\times \\
T_{21}=1.5022 \\
\times\end{array}$ & $\begin{array}{l}\times \\
Q_{21}=500 \\
\times\end{array}$ & $\begin{array}{l}\times \\
\operatorname{JTP}_{21}^{(4)}=4563.7 \leftarrow \\
\times\end{array}$ \\
\hline 5 & $\begin{array}{l}\text { Case } 1-1 \\
\text { Case 2-1 } \\
\text { Case 2-2 }\end{array}$ & $\begin{array}{l}\times \\
5 \\
\times\end{array}$ & $\begin{array}{l}\times \\
K_{21}=0.6464 \\
\times\end{array}$ & $\begin{array}{l}\times \\
T_{21}=1.8103 \\
\times\end{array}$ & $\begin{array}{l}\times \\
Q_{21}=600 \\
\times\end{array}$ & $\begin{array}{l}\times . \\
\operatorname{JTP}_{21}^{(5)}=4558.49 \leftarrow \\
\times\end{array}$ \\
\hline
\end{tabular}

Notes. " $\longleftarrow$ " denote the optimal solution for given $k$. " $\times$ " denotes the problem is not feasible in this case. " $\leftarrow$ " denotes the global optimal solution.

TABLE 4 . The result of sensitivity analysis on $W$ and $\left(N_{1}, N_{2}, N_{3}\right)$.

\begin{tabular}{|c|c|c|c|c|c|c|c|c|}
\hline$\left(N_{1}, N_{2}, N_{3}\right)$ & $W$ & $m^{*}$ & $K^{*}$ & $T^{*}$ & $Q^{*}$ & $\mathrm{JTP}^{*}$ & $\begin{array}{l}\text { Rented } \\
\text { warehouse }\end{array}$ & $\begin{array}{l}\text { Credit } \\
\text { period }\end{array}$ \\
\hline \multirow[t]{5}{*}{$(0.10,0.20,0.30)$} & 100 & 6 & 0.9208 & 0.4910 & 169.80 & 4479.02 & Yes & $N_{1}$ \\
\hline & 200 & 6 & 0.9363 & 0.5189 & 179.88 & 4485.95 & No & $N_{1}$ \\
\hline & 300 & 5 & 0.9363 & 0.5189 & 179.88 & 4485.95 & No & $N_{1}$ \\
\hline & 400 & 5 & 0.9363 & 0.5189 & 179.88 & 4484.95 & No & $N_{1}$ \\
\hline & 500 & 5 & 0.9363 & 0.5189 & 179.88 & 4485.95 & No & $N_{1}$ \\
\hline \multirow[t]{5}{*}{$(0.30,0.45,0.60)$} & 100 & 4 & 0.8975 & 0.4741 & 163.38 & 4547.56 & Yes & $N_{1}$ \\
\hline & 200 & 4 & 0.7280 & 1.0425 & 349.99 & 4581.22 & Yes & $\mathrm{N}_{2}$ \\
\hline & 300 & 4 & 0.7000 & 1.4960 & 500.04 & 4586.96 & Yes & $N_{2}$ \\
\hline & 400 & 3 & 0.6825 & 1.8000 & 600.00 & 4592.86 & Yes & $N_{3}$ \\
\hline & 500 & 3 & 0.6871 & 1.7987 & 600.00 & 4593.32 & Yes & $N_{3}$ \\
\hline \multirow[t]{5}{*}{$(0.40,0.60,0.80)$} & 100 & 3 & 0.6294 & 1.8152 & 600.00 & 4649.27 & Yes & $N_{3}$ \\
\hline & 200 & 3 & 0.6441 & 1.8110 & 600.00 & 4673.29 & Yes & $N_{3}$ \\
\hline & 300 & 3 & 0.6586 & 1.8068 & 600.00 & 4688.67 & Yes & $N_{3}$ \\
\hline & 400 & 2 & 0.6727 & 1.8028 & 600.00 & 4695.37 & Yes & $N_{3}$ \\
\hline & 500 & 2 & 0.6764 & 1.8017 & 599.99 & 4695.68 & Yes & $N_{3}$ \\
\hline
\end{tabular}

the purpose of the supply chain system is to encourage the retailer to order more units or to lower the supplier's shipment number. Second, the longer credit period set the supplier provided or the larger capacity of OW, the more benefit for the supply chain system will be. In a word, it is the best choice for the retailer to persuade the supplier to offer a longer trade the credit period schedule or to choose the supplier with a longer trade credit period. In addition, the joint total profit per unit time can be increased by expanding OW capacity appropriately. 
TABLE 5. Sensitivity analysis on the retailer's major parameters.

\begin{tabular}{|c|c|c|c|c|c|c|c|c|}
\hline Parameters & Values & $m^{*}$ & $K^{*}$ & $T^{*}$ & $Q^{*}$ & $\mathrm{JTP}^{*}$ & $\begin{array}{l}\text { Rented } \\
\text { warehouse }\end{array}$ & $\begin{array}{l}\text { Credit } \\
\text { period }\end{array}$ \\
\hline \multirow[t]{5}{*}{$A_{r}$} & 80 & 6 & 0.9640 & 0.4309 & 150.00 & 4623.44 & No & $N_{1}$ \\
\hline & 90 & 6 & 0.9414 & 0.4562 & 158.27 & 4600.60 & No & $N_{1}$ \\
\hline & 100 & 5 & 0.6997 & 1.4960 & 500.01 & 4586.96 & Yes & $N_{2}$ \\
\hline & 110 & 5 & 0.6994 & 1.4960 & 499.99 & 4580.27 & Yes & $N_{2}$ \\
\hline & 120 & 5 & 0.6678 & 1.8042 & 600.00 & 4574.55 & Yes & $N_{3}$ \\
\hline \multirow[t]{5}{*}{$D$} & 150 & 5 & 0.7490 & 1.0391 & 150.00 & 3592.59 & No & $N_{1}$ \\
\hline & 250 & 6 & 0.8393 & 0.6424 & 156.73 & 4078.27 & No & $N_{1}$ \\
\hline & 350 & 5 & 0.6997 & 1.4960 & 500.01 & 4586.96 & Yes & $N_{2}$ \\
\hline & 450 & 5 & 0.6889 & 1.3986 & 600.00 & 5180.35 & Yes & $N_{3}$ \\
\hline & 550 & 6 & 0.7099 & 1.1405 & 599.98 & 5782.04 & Yes & $N_{3}$ \\
\hline \multirow[t]{5}{*}{$h_{r}$} & 1.6 & 5 & 0.6804 & 1.8006 & 600.00 & 4590.61 & Yes & $N_{3}$ \\
\hline & 1.8 & 5 & 0.6742 & 1.8023 & 599.98 & 4588.05 & Yes & $N_{3}$ \\
\hline & 2.0 & 6 & 0.6997 & 1.4960 & 500.01 & 4586.96 & Yes & $N_{2}$ \\
\hline & 2.2 & 6 & 0.6960 & 1.4968 & 499.99 & 4586.14 & Yes & $N_{2}$ \\
\hline & 2.4 & 6 & 0.6925 & 1.4976 & 499.98 & 4585.36 & Yes & $N_{2}$ \\
\hline \multirow[t]{5}{*}{$h_{0}$} & 1.0 & 5 & 0.6984 & 1.7955 & 600.00 & 4639.05 & Yes & $N_{2}$ \\
\hline & 1.2 & 5 & 0.7178 & 1.4917 & 499.99 & 4612.27 & Yes & $N_{2}$ \\
\hline & 1.4 & 5 & 0.6997 & 1.4960 & 500.01 & 4586.96 & Yes & $N_{2}$ \\
\hline & 1.6 & 6 & 0.8858 & 0.4910 & 168.91 & 4565.68 & No & $N_{1}$ \\
\hline & 1.8 & 6 & 0.8615 & 0.4839 & 165.85 & 4552.66 & No & $N_{1}$ \\
\hline \multirow[t]{5}{*}{$c_{b}$} & 2.0 & 5 & 0.5359 & 1.8425 & 599.98 & 4669.13 & Yes & $N_{3}$ \\
\hline & 3.0 & 5 & 0.6131 & 1.8199 & 600.00 & 4620.22 & Yes & $N_{3}$ \\
\hline & 4.0 & 5 & 0.6997 & 1.4960 & 500.01 & 4586.96 & Yes & $N_{2}$ \\
\hline & 5.0 & 6 & 0.9271 & 0.4911 & 170.00 & 4579.18 & No & $N_{1}$ \\
\hline & 6.0 & 6 & 0.9382 & 0.4857 & 168.42 & 4578.85 & No & $N_{1}$ \\
\hline \multirow{5}{*}{$c_{g}$} & 0.5 & 5 & 0.6480 & 1.8098 & 599.98 & 4612.56 & Yes & $N_{3}$ \\
\hline & 1.0 & 5 & 0.6547 & 1.8079 & 599.99 & 4603.40 & Yes & $N_{3}$ \\
\hline & 2.0 & 5 & 0.6997 & 1.4960 & 500.01 & 4586.96 & Yes & $N_{2}$ \\
\hline & 3.0 & 6 & 0.9949 & 0.4602 & 160.95 & 4577.10 & No & $N_{1}$ \\
\hline & 4.0 & 6 & 1.0000 & 0.4578 & 160.23 & 4577.10 & No & $N_{1}$ \\
\hline \multirow[t]{5}{*}{$p$} & 13 & 5 & 0.6766 & 1.5014 & 500.00 & 3904.01 & Yes & $N_{2}$ \\
\hline & 14 & 5 & 0.6766 & 1.4987 & 500.00 & 4245.27 & Yes & $N_{2}$ \\
\hline & 15 & 5 & 0.6997 & 1.4960 & 500.01 & 4586.96 & Yes & $N_{2}$ \\
\hline & 16 & 6 & 0.9831 & 0.4605 & 160.77 & 4931.33 & No & $N_{1}$ \\
\hline & 17 & 6 & 1.0000 & 0.4477 & 156.69 & 5285.44 & No & $N_{1}$ \\
\hline \multirow[t]{5}{*}{$\beta$} & 0.75 & 6 & 1.0000 & 0.4578 & 160.23 & 4577.10 & No & $N_{1}$ \\
\hline & 0.80 & 6 & 1.0000 & 0.4578 & 160.23 & 4577.10 & No & $N_{1}$ \\
\hline & 0.85 & 5 & 0.6997 & 1.4960 & 500.01 & 4586.96 & Yes & $N_{2}$ \\
\hline & 0.90 & 5 & 0.6364 & 1.7790 & 600.01 & 4639.17 & Yes & $N_{3}$ \\
\hline & 0.95 & 5 & 0.6059 & 1.7487 & 599.98 & 4696.54 & Yes & $N_{3}$ \\
\hline \multirow[t]{5}{*}{$I_{R c}$} & 0.06 & 5 & 0.7238 & 1.4903 & 499.99 & 4603.49 & Yes & $N_{2}$ \\
\hline & 0.08 & 5 & 0.7114 & 1.4932 & 500.00 & 4595.00 & Yes & $N_{2}$ \\
\hline & 0.10 & 5 & 0.6997 & 1.4960 & 500.01 & 4586.96 & Yes & $N_{2}$ \\
\hline & 0.12 & 6 & 0.7358 & 1.0413 & 350.01 & 4581.72 & No & $N_{2}$ \\
\hline & 0.14 & 6 & 0.7267 & 1.0427 & 349.98 & 4578.55 & No & $N_{2}$ \\
\hline
\end{tabular}


TABLE 5. Continued.

\begin{tabular}{|c|c|c|c|c|c|c|c|c|}
\hline Parameters & Values & $m^{*}$ & $K^{*}$ & $T^{*}$ & $Q^{*}$ & $\mathrm{JTP}^{*}$ & $\begin{array}{l}\text { Rented } \\
\text { warehouse }\end{array}$ & $\begin{array}{l}\text { Credit } \\
\text { period }\end{array}$ \\
\hline \multirow[t]{5}{*}{$I_{R e}$} & 0.08 & 6 & 0.9639 & 0.4996 & 173.91 & 4557.39 & No & $N_{1}$ \\
\hline & 0.10 & 6 & 0.9371 & 0.5000 & 173.35 & 4568.17 & No & $N_{1}$ \\
\hline & 0.12 & 5 & 0.6997 & 1.4960 & 500.01 & 4586.96 & Yes & $N_{2}$ \\
\hline & 0.14 & 5 & 0.6549 & 1.8079 & 600.00 & 4614.22 & Yes & $N_{3}$ \\
\hline & 0.16 & 5 & 0.6416 & 1.8117 & 600.00 & 4643.50 & Yes & $N_{3}$ \\
\hline \multirow[t]{5}{*}{$c_{1}, c_{2}, c_{3}$} & $9,8.7,8.4$ & 6 & 0.9967 & 0.4650 & 162.67 & 4928.08 & No & $N_{1}$ \\
\hline & $9.5,9.25,9.0$ & 5 & 0.7597 & 1.0374 & 350.00 & 4737.56 & No & $\mathrm{N}_{2}$ \\
\hline & $10,9.7,9.4$ & 5 & 0.6997 & 1.4960 & 500.01 & 4586.96 & Yes & $N_{2}$ \\
\hline & $10.5,10,9.5$ & 5 & 0.6974 & 1.4965 & 500.00 & 4553.12 & Yes & $N_{2}$ \\
\hline & $11,10.6,10.2$ & 5 & 0.6536 & 1.8082 & 599.99 & 4317.14 & Yes & $N_{3}$ \\
\hline
\end{tabular}

Example 5.3. Using the same data as those in Example 5.1 except for $W=300$, this example outlines the effects of changes in the retailer's major parameters $A_{r}, D, h_{r}, h_{0}, c_{b}, g, p, \beta, I_{R c}, I_{R e}, F_{0}, F_{1}$ and $\left(c_{1}, c_{2}, c_{3}\right)$ on the optimal solutions. The results are summarized in Table 5.

Based on Table 5, the main conclusions are as follows:

(i) The joint total annual profit increases with respect to the changes of the $\mathrm{JTP}^{*}$ parameters $D, p, \beta$ and $I_{R e}$ whereas it decreases with respect to $A_{r}, h_{r}, h_{0}, c_{b}, c_{g}, I_{R c}$ and $\left(c_{1}, c_{2}, c_{3}\right)$. Understandably, the parameters $D, p, \beta$ and $I_{R e}$ have a positive influence on the joint total annual profit $\mathrm{JTP}^{*}$, so the increase of their values must bring more profits. On the contrary, the parameters $A_{r}, h_{r}, h_{0}, c_{b}, c_{g}, I_{R c}$ and $\left(c_{1}, c_{2}, c_{3}\right)$ are all cost structure parameters of inventory system, and the increase of their values must result in the decrease of total annual profit JTP*. Moreover, we observe that the annual profit $\mathrm{JTP}^{*}$ is highly sensitive to the changes of parameters $D, p$ and $\left(c_{1}, c_{2}, c_{3}\right)$.

(ii) Optimal order quantity $Q^{*}$ increases when we increase the values of parameters $A_{r}, D, I_{R e}$ and $\left(c_{1}, c_{2}, c_{3}\right)$, while it decreases with respect to changes of $h_{r}, h_{0}, c_{b}, c_{g}$, and $p$. Hence, if ordering cost $A_{r}$ increases, the retailer wants to decrease order frequency by increasing order quantity; if the demand parameter $D$ or the backlogged parameter $\beta$ increases, customers' demand also increases and consequently, the retailer needs to make a large order size. In addition, the increase of parameter $I_{R e}$ or $\left(c_{1}, c_{2}, c_{3}\right)$ will motivate retailers to order more goods to enjoy longer credit period and lower purchase price. On the other hand, if inventory holding cost $h_{r}$ or $h_{0}$ increases, the retailer will lessen order quantity to maintain a lower average inventory level. If backlogging cost $c_{b}$, lost sale $\operatorname{cost} c_{g}$ or unit selling price $p$ increases, the retailer wants to shorten the replenishment cycle and the shortages period to reduce the shortage cost and the lost sales cost. As a result, the retailer will make a small order size.

(iii) Optimal fraction of no shortage $K^{*}$ increases with respect to the changes of the parameters $c_{b}, c_{g}$ and $p$ whereas it decreases with respect to the change of parameters $A_{r}, \beta, I_{R e}$, and $\left(c_{1}, c_{2}, c_{3}\right)$. In fact, the increase in the value of parameters $c_{b}, c_{g}$ and $p$ means that the retailer will pay more for shortages. So, the retailer will shorten the shortage period, i.e., by increasing the fraction of no shortage. However, If the value of parameters $A_{r}, \beta, I_{R e}$, and $\left(c_{1}, c_{2}, c_{3}\right)$ increases, the retailer will be encouraged to make a large order size. Meanwhile, the retailer wants to lengthen the shortage period (i.e., reduce the fraction of no shortage) to avoid paying excessive inventory holding costs. In addition, we observe that when the retailer faces a discount schedule when purchase price and trade credit are both linked to the order quantity, there is no specific monotonic relationship between $K^{*}$ and the value of parameters $D, h_{r}, h_{0}$ and $I_{R c}$.

(iv) Optimal replenishment cycle $T^{*}$ increases if we change the values of the parameters $A_{r}, I_{R e}$ and $\left(c_{1}, c_{2}, c_{3}\right)$ whereas decreases if we change the values of $h_{0}, c_{b}, c_{g}, I_{R c}$ and $p$. Obviously, if the value of parameters $A_{r}$, $I_{R e}$ and $\left(c_{1}, c_{2}, c_{3}\right)$ increases, the retailer will make a large order size, and thus $T^{*}$ also will be increased. 
TABLE 6. Sensitivity analysis on the supplier's major parameters.

\begin{tabular}{lllllllllll}
\hline Parameters & Values & $m^{*}$ & $K^{*}$ & $T^{*}$ & $Q^{*}$ & $m^{*} T^{*}$ & $m^{*} Q^{*}$ & ATP $^{*}$ & STP $^{*}$ & JTP $^{*}$ \\
\hline$A_{s}$ & 160 & 6 & 0.9640 & 0.4309 & 150.00 & 2.5854 & 900.00 & 1286.77 & 1971.26 & 4558.03 \\
& 170 & 6 & 0.9414 & 0.4562 & 158.27 & 2.7372 & 949.60 & 1295.42 & 1939.05 & 4534.47 \\
& 180 & 5 & 0.6997 & 1.4960 & 500.01 & 7.4800 & 2500.07 & 1214.78 & 1106.06 & 3820.84 \\
& 190 & 5 & 0.6994 & 1.4960 & 499.99 & 7.4800 & 2499.95 & 1214.79 & 1104.61 & 3819.40 \\
& 200 & 5 & 0.6678 & 1.8042 & 600.00 & 9.0210 & 3000.01 & 1152.34 & 847.12 & 3299.46 \\
\hline$h_{s}$ & 0.6 & 5 & 0.6804 & 1.8006 & 600.00 & 9.0030 & 2999.99 & 1152.84 & 1180.26 & 4633.10 \\
& 0.7 & 5 & 0.6742 & 1.8023 & 599.98 & 9.0115 & 2999.89 & 1152.681 & 1015.07 & 4467.75 \\
& 0.8 & 6 & 0.6997 & 1.4960 & 500.01 & 7.4800 & 2500.07 & 1214.78 & 1106.06 & 3620.84 \\
& 0.9 & 6 & 0.6960 & 1.4968 & 499.99 & 8.9808 & 2999.95 & 1214.76 & 761.40 & 3276.16 \\
& 1.0 & 6 & 0.6925 & 1.4976 & 499.98 & 8.9856 & 2999.90 & 1214.69 & 603.56 & 3118.26 \\
\hline$I_{S p}$ & 0.08 & 5 & 0.7238 & 1.4903 & 499.99 & 7.4515 & 2499.97 & 1214.01 & 1166.33 & 3680.34 \\
& 0.09 & 5 & 0.7114 & 1.4932 & 500.00 & 7.4660 & 2499.98 & 1214.62 & 1136.03 & 3650.66 \\
& 0.10 & 5 & 0.6997 & 1.4960 & 500.01 & 7.4800 & 2500.07 & 1214.78 & 1106.06 & 3620.84 \\
& 0.11 & 6 & 0.7358 & 1.0413 & 350.01 & 6.2478 & 2100.07 & 1293.41 & 1328.30 & 3611.70 \\
& 0.12 & 6 & 0.7267 & 1.0427 & 349.98 & 6.2562 & 2099.90 & 1293.26 & 1302.77 & 3601.03 \\
\hline
\end{tabular}

Similarly, if the value of parameters of $h_{0}, c_{b}, c_{g}, I_{R c}$ and $p$ increases, the retailer will reduce their order quantity, and eventually $T^{*}$ will be decreased. Moreover, optimal replenishment cycle $T^{*}$ is highly sensitive to the changes of parameters $A_{r}, D, h_{0}, c_{b}, c_{g}, p, \beta, I_{R e}$ and $\left(c_{1}, c_{2}, c_{3}\right)$.

(v) As the value of $A_{r}, D, \beta, I_{R e}$ and $\left(c_{1}, c_{2}, c_{3}\right)$ increases, the retailer prefers to rent an additional warehouse, while as the value of $h_{r}, h_{0}, c_{b}, c_{g}, p$ and $I_{R c}$ increases, the retailer tends to choose not to rent an additional warehouse.

Example 5.4. This example highlights the effects of changes in the supplier's major parameters $A_{s}, h_{s}$, and $I_{S p}$ on the optimal solution.

The results in Table 6 show that $\operatorname{JTP}^{*}\left(m^{*} T^{*}\right.$ and $\left.m^{*} Q^{*}\right)$ decreases (increase) as $A_{s}$ increases. The results show that the supplier has a longer production cycle length and higher production quantity at higher setup cost. Furthermore, $\mathrm{JTP}^{*}, m^{*} T^{*}$, and $m^{*} Q^{*}$ decrease as $h_{s}$ or $I_{S p}$ increase. It is clear that the supplier has a shorter production cycle length and smaller production quantity at higher holding cost and capital opportunity cost.

\section{Conclusion}

In this paper, we develop an integrated inventory model with capacity constraint under order-size dependent trade credit, all-units discount and partial backordering. In order to obtain the global optimal solution, the conditions of the objective functions to have interior minimizers are established and then a closed-form optimal solution is found. An algorithm is proposed to reveal the optimal solutions. Furthermore, numerical examples are given to demonstrate the solution procedures and a sensitivity analysis of the optimal solutions with respect to major parameters are presented and meaningful insights are gained. This study provides a useful managerial insight, for instance, that it is the best choice for the retailer to convince the supplier to offer a longer trade credit period schedule or choose the supplier with a longer trade credit period. The retailer also can increase their profits by expanding OW capacity appropriately.

Future research could modify or extend the present model in several ways. First, in this study a single-supplier and a single- retailer for a single product were considered. This foundation could be further extended to more practical situations, such as considering multiple retailers or multiple items, or taking raw material supply into account. Other possible extensions are to formulate the demand as a function of the length of the allowable 
payment delay time and the other factors, or to examine the interactions between the supplier and the retailer from the perspective of game theory. Finally, it would be of significant interest to relax the deterministic assumptions, such as demand rate, defective rate, and backorder rate; and thus extend the methodology to operate in an uncertain or stochastic environment.

\section{Appendix A.}

$$
\begin{aligned}
\varphi_{111} & =\frac{D}{2}\left[h_{0}+c_{b} \beta+c_{j} I_{R c}\right], \varphi_{112}=c_{b} \beta D, \\
\varphi_{113} & =\left[\left(p-F_{1}+c_{g}-c\right) D(1-\beta)-c_{j} I_{S p} M_{j} D(1-\beta)+\left(c_{j} I_{R c}-p \beta I_{R e}\right) D M_{j}\right], \\
\varphi_{114} & =\frac{D}{2}\left[c_{b} \beta+c\left(h_{s}+I_{S p}\right)\{(m-1)(1-\rho)+\rho\}\right], \varphi_{115}=\left\{A_{r}+F_{0}+\frac{A_{s}}{m}+\frac{\left(c_{j} I_{R c}-p I_{R e}\right) D M_{j}^{2}}{2}\right\}, \text { and } \\
\varphi_{116} & =c_{g} D(1-\beta)+\left(c+F_{1}-p\right) D \beta+\left(c_{j} I_{S p}-p I_{R e}\right) D \beta M_{j} . \\
\varphi_{121} & =\frac{D}{2}\left[h_{0}+c_{b} \beta+p I_{R e}\right] \\
\varphi_{122} & =c_{b} \beta D \\
\varphi_{123} & =\left[\left(p-F_{1}+c_{g}-c\right) D(1-\beta)+\left(p I_{R e}-c_{j} I_{S p}\right) D M_{j}(1-\beta)\right] \varphi_{124} \\
& =\frac{D}{2}\left[c_{b} \beta+c\left(h_{s}+I_{S p}\right)\{(m-1)(1-\rho)+\rho\}\right] \\
\varphi_{125} & =\left\{A_{r}+F_{0}+\frac{A_{s}}{m}\right\} \\
\varphi_{126} & =c_{g} D(1-\beta)+\left(c+F_{1}-p\right) D \beta+\left(c_{j} I_{S p}-p I_{R e}\right) D \beta M_{j} \\
\varphi_{211} & =\frac{D}{2}\left[h_{r}+c_{b} \beta+c_{j} I_{R c}\right] \\
\varphi_{212} & =c_{b} \beta D \\
\varphi_{213} & =\left[\left(p-F_{1}+c_{g}-c\right) D(1-\beta)+\left(h_{r}-h_{0}\right) w-c_{j} I_{S p} M_{j} D(1-\beta)+\left(c_{j} I_{R c}-p \beta I_{R e}\right) D M_{j}\right] \\
\varphi_{214} & =\frac{D}{2}\left[c_{b} \beta+c\left(h_{s}+I_{S p}\right)\{(m-1)(1-\rho)+\rho\}\right] \\
\varphi_{215}= & \left\{A_{r}+F_{0}+\frac{A_{s}}{m}+\frac{\left(c_{j} I_{R c}-p I_{R e}\right) D M_{j}^{2}}{2}+\frac{\left(h_{r}-h_{o}\right) W^{2}}{2 D}\right\} \\
\varphi_{216}= & c_{g} D(1-\beta)+\left(c+F_{1}-p\right) D \beta+\left(c_{j} I_{S p}-p I_{R e}\right) D \beta M_{j} \\
\varphi_{221}= & \frac{D}{2}\left[h_{r}+c_{b} \beta+p I_{R e}\right] \\
\varphi_{222}= & c_{b} \beta D \\
\varphi_{224} & =\left[\left(p-F_{1}+c_{g}-c\right) D(1-\beta)+\left(h_{r}-h_{0}\right) w+\left(p I_{R e}-c_{j} I_{S p}\right) D M_{j}(1-\beta)\right] \\
\varphi_{226} & =c_{g} D(1-\beta)+\left(c+F_{1}-p\right) D \beta+\left(c_{j} I_{S p}-p I_{R e}\right) D \beta M_{j} . \\
&
\end{aligned}
$$


Appendix B. Find the roots $\left(K_{11}, T_{11}\right),\left(K_{12}, T_{12}\right),\left(K_{21}, T_{21}\right)$, And $\left(K_{22}, T_{22}\right)$

Case 1-1: $M_{j} \leq K T \leq T_{w}$

From equation (4.2), differentiating $\operatorname{JTP}_{11}^{(j)}(m, K, T)$ with respect to $K$ and $T$, we have

$$
\begin{gathered}
\frac{\partial \operatorname{JTP}_{11}^{(j)}(m, K, T)}{\partial K}=2 \varphi_{111} K T-\varphi_{112} T-\varphi_{113} \longrightarrow K=\frac{\varphi_{112} T+\varphi_{113}}{2 \varphi_{111} T} \\
\frac{\partial \operatorname{JTP}_{11}^{(j)}(m, K, T)}{\partial T}=\varphi_{111} K^{2}-\varphi_{112} K+\varphi_{114}-\frac{\varphi_{115}}{T^{2}} \longrightarrow T^{2}=\frac{\varphi_{115}}{\varphi_{111} K^{2}-\varphi_{112} K+\varphi_{114}} .
\end{gathered}
$$

After some algebra

$$
\begin{aligned}
T_{11} & =\sqrt{\frac{4 \varphi_{111} \varphi_{115}-\varphi_{113}^{2}}{4 \varphi_{111} \varphi_{114}-\varphi_{112}^{2}}} \\
\text { and } K_{11} & =\frac{\varphi_{112}}{2 \varphi_{111}}+\frac{\varphi_{113}}{2 \varphi_{111}} \sqrt{\frac{4 \varphi_{111} \varphi_{114}-\varphi_{112}^{2}}{4 \varphi_{111} \varphi_{115}-\varphi_{113}^{2}}}
\end{aligned}
$$

Similarly, for Case 1-2, Case 2-1 and Case 2-2, the roots $\left(K_{12}, T_{12}\right),\left(K_{21}, T_{21}\right)$, and $\left(K_{22}, T_{22}\right)$ can be obtained easily.

\section{Appendix C. Find the optimal values of $T^{\#}$ When $K=1$}

Case 1-1: $M_{j} \leq K T \leq T_{w}$

Substituting $K_{11}=1$ into equation (4.2) leads to

$$
\operatorname{JTP}_{11}^{(j)}(m, 1, T)=\varphi_{111} T-\varphi_{112} T-\varphi_{113}+\varphi_{114} T+\frac{\varphi_{115}}{T}+\varphi_{116} .
$$

Taking the first and second derivatives of equation (B.1) with respect to $T$, we have

$$
\begin{aligned}
\frac{\mathrm{d} J T P_{11}^{(j)}(m, 1, T)}{\mathrm{d} T} & =\varphi_{111}-\varphi_{112}+\varphi_{114}-\frac{\varphi_{115}}{T^{2}} \\
\frac{\mathrm{d}^{2} \operatorname{JTP}_{11}^{(j)}(m, 1, T)}{\mathrm{d} T^{2}} & =\frac{2 \varphi_{115}}{T^{3}} .
\end{aligned}
$$

Obviously, if $\varphi_{115}>0$, then $\operatorname{JTP}_{11}^{(j)}(m, 1, T)$ is a strictly convex function of $T$. Setting $\operatorname{JTP}_{11}^{\prime(j)}(m, 1, T)=0$ yields

$$
T_{11}^{\#}=\sqrt{\frac{\varphi_{115}}{\varphi_{111}-\varphi_{112}+\varphi_{114}}} .
$$

Similarly, for the other cases, $T^{\#}$ can be obtained when $K_{12}=1, K_{21}=1$, and $K_{22}=1$,

$$
\begin{aligned}
& T_{12}^{\#}=\sqrt{\frac{\varphi_{125}}{\varphi_{121}-\varphi_{122}+\varphi_{124}}} \\
& T_{21}^{\#}=\sqrt{\frac{\varphi_{215}}{\varphi_{211}-\varphi_{212}+\varphi_{214}}} \\
& T_{11}^{\#}=\sqrt{\frac{\varphi_{225}}{\varphi_{221}-\varphi_{222}+\varphi_{224}}} .
\end{aligned}
$$




\section{Appendix D. Find the optimal values of $T^{\prime}$ AND $K^{\prime}$}

For the solution of $K_{11}$ and $T_{11}$ derived for Case 1-1, if the relationship $K_{11} T_{11}<M_{j}$ is established, it shows that the optimal values will be obtained on the boundary point. Thus, we may set $T=\frac{M_{j}}{K_{11}}$ and then substitute it into equation (4.2), which leads to

$$
\operatorname{JTP}_{11}^{(j)}\left(m, K_{11}, \frac{M_{j}}{K_{11}}\right)=\varphi_{111} K_{11}^{2} \frac{M_{j}}{K_{11}}-\varphi_{112} K_{11} \frac{M_{j}}{K_{11}}-\varphi_{113} K_{11}+\varphi_{114} \frac{M_{j}}{K_{11}}+\frac{\varphi_{115} K_{11}}{M_{j}}+\varphi_{116}
$$

Taking the first and second derivatives of equation (C.1) with respect to $K_{11}$, we have

$$
\begin{aligned}
\frac{\mathrm{dJTP}_{11}^{(j)}\left(m, K_{11}, \frac{M_{j}}{K_{11}}\right)}{\mathrm{d} K_{11}} & =\varphi_{111} M_{j}-\varphi_{113}-\varphi_{114} \frac{M_{j}}{K_{11}^{2}}+\frac{\varphi_{115}}{M_{j}} \\
\frac{\mathrm{d}^{2} \operatorname{JTP}_{11}^{(j)}\left(m, K_{11}, \frac{M_{j}}{K_{11}}\right)}{\mathrm{d} K_{11}^{2}} & =\frac{2 \varphi_{114} M_{j}}{K_{11}^{3}}>0 .
\end{aligned}
$$

From equation (C.3), $\operatorname{JTP}_{11}^{(j)}\left(m, K_{11}, \frac{M_{j}}{K_{11}}\right)$ is a strictly convex function of $K_{11}$. Setting $\operatorname{JTP}_{11}^{\prime(j)}\left(m, K_{11}, \frac{M_{j}}{K_{11}}\right)=$ 0 yields

$$
K_{11}^{\prime}=\sqrt{\frac{\varphi_{114} M_{j}^{2}}{\varphi_{111} M_{j}^{2}-\varphi_{113} M_{j}+\varphi_{115}}} .
$$

Noticing that, if $K_{11}^{\prime}$ is feasible, the optimal solution in this case is $\left(T_{11}, K_{11}\right)=\left(\frac{M_{j}}{K_{11}^{\prime}}, K_{11}^{\prime}\right)$. Otherwise the optimal solution is $\left(T_{11}, K_{11}\right)=\left(M_{j}, 1\right)$.

In addition, if the relationship $K_{11} T_{11}>T_{w}$ is established, use the same approach to develop $K_{11}^{\prime}, K_{11}^{\prime}=$ $\sqrt{\frac{\varphi_{114} T_{w}^{2}}{\varphi_{111} T_{w}^{2}-\varphi_{113} T_{w}+\varphi_{115}}}$.

In the same way, we can analyze Case 1-2, Case 2-1, Case 2-2. The specific computational results are summarized in Table 2.

\section{Appendix E. Find the optimal values of $T^{\prime \prime}$ AND $K^{\prime \prime}$ When optimal order QUANTITY $Q_{j} \notin\left[q_{j}, q_{j+1}\right)$}

If $Q_{j} \notin\left[q_{j}, q_{j+1}\right)$, there are two situations:

(1) if $Q_{j} \geq q_{j+1}$, the optimal solution does not exist and then the retailer needs to adjust the order quantity;

(2) if $Q_{j}<q_{j}$, the optimal values will be obtained at point $T=\frac{q_{j}}{D[(1-\beta) K+\beta]}$.

Based on the analysis above, we only need to discuss the case of $Q_{j}<q_{j}$.

First, for Case 1-1, substituting $T=\frac{q_{j}}{D[(1-\beta) K+\beta]}$ into equation (4.2) leads to

$$
\begin{aligned}
\operatorname{JTP}_{11}^{(j)}(m, K)= & {\left[\left\{h_{0}+c_{b} \beta+c_{j} I_{R c}\right\} K^{2}-2 c_{b} \beta K+\left[c_{b} \beta+c\left(h_{s}+I_{S p}\right)\{(m-1)(1-\rho)+\rho\}\right]\right] } \\
& \times\left(\frac{q_{j}}{2[(1-\beta) K+\beta]}\right)-\left[\left(p-c_{j}+c_{g}\right) D(1-\beta)+\left(c_{j} I_{R c}-p \beta I_{R e}\right) D M_{j}\right] K \\
& +\frac{D[(1-\beta) K+\beta]}{q_{j}}\left\{A_{r}+F_{0}+\frac{A_{s}}{m}+\frac{\left(c_{j} I_{R c}-p I_{R e}\right) D M_{j}^{2}}{2}\right\} \\
& +\left\{\left(c_{g}-c_{j}\right) D(1-\beta)-p D \beta+F_{1} D+\left(c_{j} I_{S p}-p \beta I_{R e}\right) D M_{j}+c D\right\} .
\end{aligned}
$$


Taking the first and second derivatives of equation (E.1) with respect to $K$, we have

$$
\begin{aligned}
\frac{\mathrm{dJTP}_{11}^{(j)}(m, K)}{\mathrm{d} K}= & \frac{-q_{j}(1-\beta)}{2[(1-\beta) K+\beta]^{2}}\left[\left\{h_{0}+c_{b} \beta+c_{j} I_{R c}\right\} K^{2}-2 c_{b} \beta K+\left[c_{b} \beta+c\left(h_{s}+I_{S p}\right)\{(m-1)\right.\right. \\
& \times(1-\rho)+\rho\}]]+\frac{q_{j}}{[(1-\beta) K+\beta]}\left[K\left\{h_{0}+c_{b} \beta+c_{j} I_{R c}\right\}-c_{b} \beta\right]-\left[\left(p-c_{j}+c_{g}\right) D(1-\beta)\right. \\
& \left.+\left(c_{j} I_{R c}-p \beta I_{R e}\right) D M_{j}\right]+\frac{D(1-\beta)}{q_{j}}\left\{A_{r}+F_{0}+\frac{A_{s}}{m}+\frac{\left(c_{j} I_{R c}-p I_{R e}\right) D M_{j}^{2}}{2}\right\} \\
\frac{\mathrm{d}^{2} \mathrm{JTP}_{11}^{(j)}(m, K)}{\mathrm{d} K^{2}}= & \frac{q_{j}(1-\beta)^{2}}{[(1-\beta) K+\beta]^{3}}\left[\left\{h_{0}+c_{b} \beta+c_{j} I_{R c}\right\} K^{2}-2 c_{b} \beta \mathrm{K}+\left[c_{b} \beta+c\left(h_{s}+I_{S p}\right)\{(m-1)\right.\right. \\
& \times(1-\rho)+\rho\}]]+\frac{q_{j}\left\{h_{0}+c_{b} \beta+c_{j} I_{R c}\right\}}{[(1-\beta) K+\beta]} \\
& +\frac{q_{j}(1-\beta)}{[(1-\beta) K+\beta]^{2}}\left\{c_{b} \beta-K\left(h_{0}+c_{b} \beta+c_{j} I_{R c}\right)\right\} .
\end{aligned}
$$

From equation (E.3), we know that $\operatorname{JTP}_{11}^{(j)}(m, K)$ is convex. Setting $\operatorname{dJTP}_{11}^{(j)}(m, K) / \mathrm{d} K=0$ yields

$$
\begin{aligned}
& \frac{-q_{j}(1-\beta)}{2[(1-\beta) K+\beta]^{2}}\left[\left\{h_{0}+c_{b} \beta+c_{j} I_{R c}\right\} K^{2}-2 c_{b} \beta K+\left[c_{b} \beta+c\left(h_{s}+I_{S p}\right)\{(m-1)(1-\rho)+\rho\}\right]\right] \\
& \quad+\frac{q_{j}}{[(1-\beta) K+\beta]}\left[K\left\{h_{0}+c_{b} \beta+c_{j} I_{R c}\right\}-c_{b} \beta\right]-\left[\left(p-c_{j}+c_{g}\right) D(1-\beta)\right. \\
& \left.\quad+\left(c_{j} I_{R c}-p \beta I_{R e}\right) D M_{j}\right]+\frac{D(1-\beta)}{q_{j}}\left\{A_{r}+F_{0}+\frac{A_{s}}{m}+\frac{\left(c_{j} I_{R c}-p I_{R e}\right) D M_{j}^{2}}{2}\right\}=0 .
\end{aligned}
$$

After some transformation, the equation (E.4) can be simplified to

$$
\mu_{111} K^{2}+\mu_{112} K+\mu_{113}=0
$$

where,

$$
\begin{aligned}
\mu_{111}= & 2(1-\beta)^{2} \omega_{111}-q_{j}(1-\beta)\left(h_{0}+c_{b} \beta+c_{j} I_{R c}\right) \\
\mu_{112}= & 4 \beta(1-\beta) \omega_{111}-2 q_{j} \beta\left(h_{0}+c_{b} \beta+c_{j} I_{R c}\right) \\
\mu_{113}= & 2 \omega_{111} \beta^{2}+q_{j}(1-\beta)+q_{j}(1-\beta)\left\{c_{b} \beta+c\left(h_{s}+I_{S p}\right)\{(m-1)(1-\rho)+\rho\}\right\}+2 q_{j} c_{b} \beta^{2} \\
\omega_{111}= & {\left[\left(p-c_{j}+c_{g}\right) D(1-\beta)+\left(c_{j} I_{R c}-p \beta I_{R e}\right) D M_{j}\right] } \\
& -\frac{D(1-\beta)}{q_{j}}\left\{A_{r}+F_{0}+\frac{A_{s}}{m}+\frac{\left(c_{j} I_{R c}-p I_{R e}\right) D M_{j}^{2}}{2}\right\} .
\end{aligned}
$$

For the quadratic equation (E.5), if it has roots (i.e., $\Delta=\mu_{112}-4 \mu_{111} \mu_{113} \geq 0$ ), then we have

$$
K_{11}^{\prime \prime}=\frac{-\mu_{112}+\sqrt{\mu_{112}^{2}-4 \mu_{111} \mu_{113}}}{2 \mu_{111}} .
$$

If $K_{11}^{\prime \prime}$ is feasible, then we obtain the retailer's replenishment cycle

$$
T_{11}^{\prime \prime}=\frac{q_{j}}{D\left[(1-\beta) K_{11}^{\prime \prime}+\beta\right]} .
$$

If $K_{11}^{\prime \prime}$ is not feasible or equation (E.5) has no root, we may set $K_{11}^{\prime \prime}=0$ or $K_{11}^{\prime \prime}=1$. 
In summary, for the solution of $K_{11}^{\prime \prime}$ and $T_{11}^{\prime \prime}$ derived for Case 1-1, we also need to check whether the constraint $M_{j} \leq K_{11}^{\prime \prime} T_{11}^{\prime \prime} \leq T_{w}$ is satisfied. If the constraint is valid, the optimal solution is obtained. Otherwise, the optimal solution does not exist.

Following the same steps used in Case 1-1, we can analyze Case 1-2, Case 2-1 and Case 2-2 separately.

$$
K_{12}^{\prime \prime}=\frac{-\mu_{122}+\sqrt{\mu_{122}^{2}-4 \mu_{121} \mu_{123}}}{2 \mu_{121}}
$$

where,

$$
\begin{aligned}
& \mu_{121}=2(1-\beta)^{2} \omega_{121}-q_{j}(1-\beta)\left(h_{0}+c_{b} \beta+p I_{R e}\right) \\
& \mu_{122}=4 \beta(1-\beta) \omega_{121}-2 q_{j} \beta\left(h_{0}+c_{b} \beta+p I_{R e}\right) \\
& \mu_{123}=2 \omega_{121} \beta^{2}+q_{j}(1-\beta)\left\{c_{b} \beta+c\left(h_{s}+I_{S p}\right)\{(m-1)(1-\rho)+\rho\}\right\}+2 q_{j} c_{b} \beta^{2} \\
& \omega_{121}=\left[\left(p-c_{j}+c_{g}\right) D(1-\beta)+(1-\beta) p D I_{R e} M_{j}\right]-\frac{D(1-\beta)}{q_{j}}\left\{A_{r}+F_{0}+\frac{A_{s}}{m}\right\} \\
& K_{21}^{\prime \prime}=\frac{-\mu_{212}+\sqrt{\mu_{212}^{2}-4 \mu_{211} \mu_{213}}}{2 \mu_{211}}
\end{aligned}
$$

where,

$$
\begin{aligned}
\mu_{211}= & 2(1-\beta)^{2} \omega_{211}-q_{j}(1-\beta)\left(h_{r}+c_{b} \beta+c_{j} I_{R c}\right) \\
\mu_{212}= & 4 \beta(1-\beta) \omega_{211}-2 q_{j} \beta\left(h_{r}+c_{b} \beta+c_{j} I_{R c}\right) \\
\mu_{213}= & 2 \omega_{211} \beta^{2}+q_{j}(1-\beta)\left\{c_{b} \beta+c\left(h_{s}+I_{S p}\right)\{(m-1)(1-\rho)+\rho\}\right\}+2 q_{j} c_{b} \beta^{2} \\
\omega_{211}= & {\left[\left(p-c_{j}+c_{g}\right) D(1-\beta)+\left(h_{r}-h_{0}\right) W+\left(c_{j} I_{R c}-p \beta I_{R e}\right) D M_{j}\right] } \\
& -\frac{D(1-\beta)}{q_{j}}\left\{\begin{array}{l}
\left.A_{r}+F_{0}+\frac{A_{s}}{m}+\frac{\left(c_{j} I_{R c}-p I_{R e}\right) D M_{j}^{2}}{2}+\frac{\left(h_{r}-h_{0}\right) W^{2}}{2 D}\right\} \\
K_{22}^{\prime \prime}=\frac{-\mu_{222}+\sqrt{\mu_{222}^{2}-4 \mu_{221} \mu_{223}}}{2 \mu_{221}}
\end{array}\right.
\end{aligned}
$$

where,

$$
\begin{aligned}
\mu_{221}= & 2(1-\beta)^{2} \omega_{221}-q_{j}(1-\beta)\left(h_{r}+c_{b} \beta+p I_{R e}\right) \\
\mu_{222}= & 4 \beta(1-\beta) \omega_{221}-2 q_{j} \beta\left(h_{r}+c_{b} \beta+p I_{R e}\right) \\
\mu_{223}= & 2 \omega_{221} \beta^{2}+q_{j}(1-\beta)\left\{c_{b} \beta+c\left(h_{s}+I_{S p}\right)\{(m-1)(1-\rho)+\rho\}\right\}+2 q_{j} c_{b} \beta^{2} \\
\omega_{221}= & {\left[\left(p-c_{j}+c_{g}\right) D(1-\beta)+\left(h_{r}-h_{0}\right) W+(1-\beta) p D I_{R e} M_{j}\right] } \\
& -\frac{D(1-\beta)}{q_{j}}\left\{A_{r}+F_{0}+\frac{A_{s}}{m}+\frac{\left(h_{r}-h_{0}\right) W^{2}}{2 D}\right\} .
\end{aligned}
$$

\section{Appendix F. Algorithm A: Determine $\left(K_{11}^{* *}, T_{11}^{* *}\right) \operatorname{And} \operatorname{JTP}_{11}^{(j)}\left(m, K_{11}^{* *}, T_{11}^{* *}\right)$}

A1. Calculate $\varphi_{11 i}(i=1,2, \ldots, 6)$ from equations (4.3) to (4.9). If $\varphi_{115}>0$, go to step A2; if not, go to step A6.

A2. Calculate $\beta_{11}$ from equation (4.18), if $\beta \leq \beta_{11}$, go to step A4; else if $\beta>\beta_{11}$, calculate $T_{11}$ from equation (4.19). If $T_{11}$ is feasible, go to step A3; if not, go to step A4.

A3. Compute $K_{11}$ from equation (4.20), if $K_{11} \leq 1$, go to step A5; if not, go to step A4. 
A4. Set $K_{11}=1$, determine $T_{11}^{\#}$ from equations in Appendix A. If $T_{11}^{\#}>T_{w}$, set $\left(K_{11}^{*}, T_{11}^{*}\right)=\left(1, T_{w}\right)$ and go to step A7; else if $T_{11}^{\#}<M_{j}$, set $\left(K_{11}^{*}, T_{11}^{*}\right)=\left(1, M_{j}\right)$ and go to step A7; otherwise, set $\left(K_{11}^{*}, T_{11}^{*}\right)=\left(1, T_{11}^{\#}\right)$ and go to step A7.

A5. If $M_{j} \leq K_{11} T_{11} \leq T_{w}$, set $\left(K_{11}^{*}, T_{11}^{*}\right)=\left(K_{11}, T_{11}\right)$ and go to step A7; if not, go to step A6.

A6. If $K_{11} T_{11}>T_{w}$, obtain $\left(K_{11}^{*}, T_{11}^{*}\right)=\left(K_{11}^{\prime}, T_{11}^{\prime}\right)$ by employing Table 2 . Then if $T_{11}^{*}$ and $K_{11}^{*}$ are feasible, go to step A7; if not, go to step A4. On the other hand, if $K_{11} T_{11}<M_{j}$, obtain $\left(K_{11}^{*}, T_{11}^{*}\right)=\left(K_{11}^{\prime}, T_{11}^{\prime}\right)$ using Table 2. Now, if $T_{11}^{*}$ and $K_{11}^{*}$ are feasible, go to step A7; if not, go to step A4.

A7. Calculate order quantity $Q_{j}=D T_{11}^{*}\left[\left(1-K_{11}^{*}\right) \beta+K_{11}^{*}\right]$ from equation (4.21), and go to step A8.

A8. Determine the relationship between $Q_{j}$ and $\left[q_{j}, q_{j+1}\right)$ using the following sub-steps.

A8.1. If $q_{j} \leq Q_{j}<q_{j+1}$, set $\left(K_{11}^{* *}, T_{11}^{* *}\right)=\left(K_{11}^{*}, T_{11}^{*}\right)$. Calculate the retailer's annual profit $\operatorname{JTP}_{11}^{(j)}\left(m, K_{11}^{* *}, T_{11}^{* *}\right)$ using equation (3.13) and go to step A9.

A8.2. If $Q_{j} \geq q_{j+1}$, then $T_{11}^{*}$ and $K_{11}^{*}$ are not feasible solutions, set $\operatorname{JTP}_{11}^{(j)}(m, K, T)=-$ inf.

A8.3. If $Q_{j}<q_{j}$, then $T_{11}^{*}$ and $K_{11}^{*}$ are not feasible solutions. However, $\operatorname{JTP}_{11}^{(j)}(m, K, T)$ at point $T=$ $\frac{q_{j}}{D[(1-\beta) K+\beta]}$ has a maximum value. Thus, calculate $K_{11}^{\prime \prime}$ from equations in Appendix D. If $K_{11}^{\prime \prime}$ is feasible, go to step A8.3.1; if not, go to step A8.3.2.

A8.3.1. If $M_{j} \leq K_{11}^{\prime \prime} T_{11}^{\prime \prime} \leq T_{w}$, set $\left(K_{11}^{* *}, T_{11}^{* *}\right)=\left(K_{11}^{\prime \prime}, T_{11}^{\prime \prime}\right)$, and calculate the retailer's annual profit $\operatorname{JTP}_{11}^{(j)}\left(m, K_{11}^{* *}, T_{11}^{* *}\right)$ using equation (3.13), go to step A9. Otherwise, $T_{11}^{\prime \prime}$ and $K_{11}^{\prime \prime}$ are not feasible solutions, set $\operatorname{JTP}_{11}^{(j)}(m, K, T)=-$ inf, go to step A9.

A8.3.2. Let $K_{11}^{\prime \prime}=1$ and $T_{11}^{\prime \prime}=q_{j} / D$. If $M_{j} \leq K_{11}^{\prime \prime} T_{11}^{\prime \prime} \leq T_{w}$, set $\left(K_{11}^{* *}, T_{11}^{* *}\right)=\left(1, q_{j} / D\right)$, and calculate the retailer's annual profit $\operatorname{JTP}_{11}^{(j)}\left(m, K_{11}^{* *}, T_{11}^{* *}\right)$ using equation (3.13) and go to step A9. Otherwise, $T_{11}^{\prime \prime}$ and $K_{11}^{\prime \prime}$ are not feasible solutions, set $\operatorname{JTP}_{11}^{(j)}(m, K, T)=-$ inf, go to step A9.

A9. If $\operatorname{JTP}_{11}^{(j)}\left(m, K_{11}^{* *}, T_{11}^{* *}\right) \geq-c_{j} D$, the optimal solutions $K_{11}^{* *}$ and $T_{11}^{* *}$ are found and stop. Otherwise, go to step A10.

A10. Set $\left(K_{11}^{* *}, T_{11}^{* *}\right)=(0, \infty), \operatorname{JTP}_{11}^{(j)}\left(m, K_{11}^{* *}, T_{11}^{* *}\right)=-c_{j} D$.

\section{Appendix G. Algorithm B: Determine $\left(K_{12}^{* *}, T_{12}^{* *}\right) \operatorname{And} \operatorname{JTP}_{12}^{(j)}\left(m, K_{12}^{* *}, T_{12}^{* *}\right)$}

B1. Calculate $\varphi_{12 i}(i=1,2, \ldots, 6)$ from equations (4.23) to (4.28), go to step B2.

B2. Calculate $\beta_{12}$ from equation (B.2), if $\beta \leq \beta_{12}$, go to step B4; else if $\beta>\beta_{12}$, calculate $T_{12}$ from equation (4.17). If $T_{12}$ is feasible, go to step B3; if not, go to step B4.

B3. Compute $K_{12}$ from equation (B.4), if $K_{12} \leq 1$, go to step B5; if not, go to step B4.

B4. Set $K_{12}=1$, determine $T_{12}^{\#}$ from equations in Appendix B. If $T_{12}^{\#}>\min \left\{T_{w}, M_{j}\right\}$, set $\left(K_{12}^{*}, T_{12}^{*}\right)=$ $\left(1, \min \left\{T_{w}, M_{j}\right\}\right)$ and go to step B7; otherwise, set $\left(K_{12}^{*}, T_{12}^{*}\right)=\left(1, T_{12}^{\#}\right)$ and go to step B7.

B5. If $K_{12} T_{12} \leq \min \left\{T_{w}, M_{j}\right\}$, set $\left(K_{12}^{*}, T_{12}^{*}\right)=\left(K_{12}, T_{12}\right)$ and go to step B7; if not, go to step B6.

B6. If $K_{12} T_{12}>\min \left\{T_{w}, M_{j}\right\}$, obtain $\left(K_{12}^{*}, T_{12}^{*}\right)=\left(K_{12}^{\prime}, T_{12}^{\prime}\right)$ by employing Table 2 . Then if $T_{12}^{*}$ and $K_{12}^{*}$ are feasible, go to step B7; if not, go to step B4.

B7. Calculate order quantity $Q_{j}=D T_{12}^{*}\left[\left(1-K_{12}^{*}\right) \beta+K_{12}^{*}\right]$, and go to step B8.

B8. Determine the relationship between $Q_{j}$ and $\left[q_{j}, q_{j+1}\right)$ using the following sub-steps.

B8.1. If $q_{j} \leq Q_{j}<q_{j+1}$, set $\left(K_{12}^{* *}, T_{12}^{* *}\right)=\left(K_{12}^{*}, T_{12}^{*}\right)$. Calculate the retailer's annual profit $\operatorname{JTP}_{12}^{(j)}\left(m, K_{12}^{* *}, T_{12}^{* *}\right)$ using equation (3.14) and go to step B9.

B8.2. If $Q_{j} \geq q_{j+1}$, then $T_{12}^{*}$ and $K_{12}^{*}$ are not feasible solutions, set $\operatorname{JTP}_{12}^{(j)}\left(m, K_{12}^{*}, T_{12}^{*}\right)=-$ inf.

B8.3. If $Q_{j}<q_{j}$, then $T_{12}^{*}$ and $K_{12}^{*}$ are not feasible solutions. However, $\operatorname{JTP}_{12}^{(j)}(m, K, T)$ at point $T=$ $\frac{q_{j}}{D[(1-\beta) K+\beta]}$ has a maximum value. Thus, calculate $K_{12}^{\prime \prime}$ from equations in Appendix D. If $K_{12}^{\prime \prime}$ is feasible, go to step B8.3.1; if not, go to step B8.3.2. 
B8.3.1. If $K_{12}^{\prime \prime} T_{12}^{\prime \prime} \leq \min \left\{T_{w}, M_{j}\right\}$, set $\left(K_{12}^{* *}, T_{12}^{* *}\right)=\left(K_{12}^{\prime \prime}, T_{12}^{\prime \prime}\right)$, and calculate the retailer's annual profit $\operatorname{JTP}_{12}^{(j)}\left(m, K_{12}^{* *}, T_{12}^{* *}\right)$ using equation (3.14), go to step B9. Otherwise, $T_{12}^{\prime \prime}$ and $K_{12}^{\prime \prime}$ are not feasible solutions, set $\operatorname{JTP}_{12}^{(j)}\left(m, K_{12}^{* *}, T_{12}^{* *}\right)=-$ inf, go to step B9.

B8.3.2. Let $K_{12}^{\prime \prime}=1$ and $T_{12}^{\prime \prime}=q_{j} / D$. If $K_{12}^{\prime \prime} T_{12}^{\prime \prime} \leq \min \left\{T_{w}, M_{j}\right\}$, set $\left(K_{12}^{* *}, T_{12}^{* *}\right)=\left(1, q_{j} / D\right)$, and calculate the retailer's annual profit $\operatorname{JTP}_{12}^{(j)}\left(m, K_{12}^{* *}, T_{12}^{* *}\right)$ using equation (3.14) and go to step B9. Otherwise, $T_{11}^{\prime \prime}$ and $K_{11}^{\prime \prime}$ are not feasible solutions, set $\operatorname{JTP}_{12}^{(j)}\left(m, K_{12}^{* *}, T_{12}^{* *}\right)=-$ inf, go to step B9.

B9. If $\operatorname{JTP}_{12}^{(j)}\left(m, K_{12}^{* *}, T_{12}^{* *}\right) \geq-c_{j} D$, the optimal solutions $K_{12}^{* *}$ and $T_{12}^{* *}$ are found and stop. Otherwise, go to step B10.

B10. Set $\left(K_{12}^{* *}, T_{12}^{* *}\right)=(0, \infty), \operatorname{JTP}_{12}^{(j)}\left(m, K_{12}^{* *}, T_{12}^{* *}\right)=-c_{j} D$.

\section{Appendix H. Algorithm C: Determine $\left(K_{21}^{* *}, T_{21}^{* *}\right)$ And $\operatorname{JTP}_{21}^{(j)}\left(m, K_{21}^{* *}, T_{21}^{* *}\right)$}

C1. Calculate $\varphi_{21 i}(i=1,2, \ldots, 6)$ from equations (C.2)-(C.7). If $\varphi_{215}>0$, go to step C2; if not, go to step C6.

C2. Calculate $\beta_{21}$ from equation (D.2), if $\beta \leq \beta_{21}$, go to step C4; else if $\beta>\beta_{21}$, calculate $T_{21}$ from equation (4.22). If $T_{21}$ is feasible, go to step C3; if not, go to step C4.

C3. Compute $K_{21}$ from equation (D.4), if $K_{21} \leq 1$, go to step C5; if not, go to step C4.

C4. Set $K_{21}=1$, determine $T_{21}^{\#}$ from equations in Appendix D. If $T_{21}^{\#}<\max \left\{T_{w}, M_{j}\right\}$, set $\left(K_{21}^{*}, T_{21}^{*}\right)=$ $\left(1, \max \left\{T_{w}, M_{j}\right\}\right)$ and go to step C7. Otherwise, set $\left(K_{21}^{*}, T_{21}^{*}\right)=\left(1, T_{21}^{\#}\right)$ and go to step $\mathrm{C} 7$.

C5. If $\max \left\{T_{w}, M_{j}\right\} \leq K_{21} T_{21}$, set $\left(K_{21}^{*}, T_{21}^{*}\right)=\left(K_{21}, T_{21}\right)$ and go to step C7; if not, go to step C6.

C6. If $K_{21} T_{21}<\max \left\{T_{w}, M_{j}\right\}$, obtain $\left(K_{21}^{*}, T_{21}^{*}\right)=\left(K_{21}^{\prime}, T_{21}^{\prime}\right)$ by employing Table 2 . Then if $T_{21}^{*}$ and $K_{21}^{*}$ are feasible, go to step $\mathrm{C} 7$; if not, go to step C4.

C7. Calculate order quantity $Q_{j}=D T_{21}^{*}\left[\left(1-K_{21}^{*}\right) \beta+K_{21}^{*}\right]$, and go to step C8.

C8. Determine the relationship between $Q_{j}$ and $\left[q_{j}, q_{j+1}\right)$ using the following sub-steps.

C8.1. If $q_{j} \leq Q_{j}<q_{j+1}$, set $\left(K_{21}^{* *}, T_{21}^{* *}\right)=\left(K_{21}^{*}, T_{21}^{*}\right)$. Calculate the retailer's annual profit $\operatorname{JTP}_{21}^{(j)}\left(m, K_{21}^{* *}, T_{21}^{* *}\right)$ using equation (3.15) and go to step C9.

C8.2. If $Q_{j} \geq q_{j+1}$, then $T_{21}^{*}$ and $K_{21}^{*}$ are not feasible solutions, set $\operatorname{JTP}_{21}^{(j)}\left(m, K_{21}^{*}, T_{21}^{*}\right)=-$ inf.

C8.3. If $Q_{j}<q_{j}$, then $T_{21}^{*}$ and $K_{21}^{*}$ are not feasible solutions. However, $\operatorname{JTP}_{21}^{(j)}(m, K, T)$ at point $T=$ $\frac{q_{j}}{D[(1-\beta) K+\beta]}$ has a maximum value. Thus, calculate $K_{21}^{\prime \prime}$ from Algorithm A in Appendix F. If $K_{21}^{\prime \prime}$ is feasible, go to step C8.3.1; if not, go to step C8.3.2.

C8.3.1. If $\max \left\{T_{w}, M_{j}\right\} \leq K_{21}^{\prime \prime} T_{21}^{\prime \prime}$, set $\left(K_{21}^{* *}, T_{21}^{* *}\right)=\left(K_{21}^{\prime \prime}, T_{21}^{\prime \prime}\right)$, and calculate the retailer's annual profit $\mathrm{JTP}_{21}^{(j)}\left(m, K_{21}^{* *}, T_{21}^{* *}\right)$ using equation (3.15), go to step C9. Otherwise, $T_{21}^{\prime \prime}$ and $K_{21}^{\prime \prime}$ are not feasible solutions, set $\operatorname{JTP}_{21}^{(j)}\left(m, K_{21}^{* *}, T_{21}^{* *}\right)=-$ inf, go to step C9.

C8.3.2. Let $K_{21}^{\prime \prime}=1$ and $T_{21}^{\prime \prime}=q_{j} / D$. If $\max \left\{T_{w}, M_{j}\right\} \leq K_{21}^{\prime \prime} T_{21}^{\prime \prime}$, set $\left(K_{21}^{* *}, T_{21}^{* *}\right)=\left(1, q_{j} / D\right)$, and calculate the retailer's annual profit $\operatorname{JTP}_{21}^{(j)}\left(m, K_{21}^{* *}, T_{21}^{* *}\right)$ using equation (3.15) and go to step C9. Otherwise, $T_{21}^{\prime \prime}$ and $K_{21}^{\prime \prime}$ are not feasible solutions, set $\operatorname{JTP}_{21}^{(j)}\left(m, K_{21}^{* *}, T_{21}^{* *}\right)=-$ inf, go to step C9.

C9. If $\operatorname{JTP}_{21}^{(j)}\left(m, K_{21}^{* *}, T_{21}^{* *}\right) \geq-c_{j} D$, the optimal solutions $K_{21}^{* *}$ and $T_{21}^{* *}$ are found and stop. Otherwise, go to step $\mathrm{C} 10$.

C10. Set $\left(K_{21}^{* *}, T_{21}^{* *}\right)=(0, \infty), \operatorname{JTP}_{21}^{(j)}\left(m, K_{21}^{* *}, T_{21}^{* *}\right)=-c_{j} D$.

\section{Appendix I. Algorithm D: Determine $\left(K_{22}^{* *}, T_{22}^{* *}\right) \operatorname{And} \operatorname{JTP}_{22}^{(j)}\left(m, K_{22}^{* *}, T_{22}^{* *}\right)$}

D1. Calculate $\varphi_{22 i}(i=1,2, \ldots, 6)$ from equations (E.2)-(E.7), go to step D6.

D2. Calculate $\beta_{22}$ from equation (E.8), if $\beta \leq \beta_{22}$, go to step D4; else if $\beta>\beta_{22}$, calculate $T_{22}$ from equation (E.9). If $T_{22}$ is feasible, go to step D3; if not, go to step D4.

D3. Compute $K_{22}$ from equation (E.10), if $K_{22} \leq 1$, go to step D5; if not, go to step-D4. 
D4. Set $K_{22}=1$, determine $T_{22}^{\#}$ from equation (D7) in Appendix D. If $T_{22}^{\#}<T_{w}$, set $\left(K_{22}^{*}, T_{22}^{*}\right)=\left(1, T_{w}\right)$ and go to step D7; else if $T_{22}^{\sharp}>M_{j}$, set $\left(K_{22}^{*}, T_{22}^{*}\right)=\left(1, M_{j}\right)$ and go to step D7; Otherwise, set $\left(K_{22}^{*}, T_{22}^{*}\right)=\left(1, T_{22}^{\sharp}\right)$ and go to step D7.

D5. If $T_{w} \leq K_{22} T_{22} \leq M_{j}$, set $\left(K_{22}^{*}, T_{22}^{*}\right)=\left(K_{22}, T_{22}\right)$ and go to step D7; if not, go to step D6.

D6. If $K_{22} T_{22}<T_{w}$, obtain $\left(K_{22}^{*}, T_{22}^{*}\right)=\left(K_{22}^{\prime}, T_{22}^{\prime}\right)$ by employing Table 2 . Then if $T_{22}^{*}$ and $K_{22}^{*}$ are feasible, go to step D7; if not, go to step D4. On the other hand, if $K_{22} T_{22}>M_{j}$, obtain $\left(K_{22}^{*}, T_{22}^{*}\right)=\left(K_{22}^{\prime}, T_{22}^{\prime}\right)$ using Table 2. Now, if $T_{22}^{*}$ and $K_{22}^{*}$ are feasible, go to step D7; if not, go to step D4.

D7. Calculate order quantity $Q_{j}=D T_{22}^{*}\left[\left(1-K_{22}^{*}\right) \beta+K_{22}^{*}\right]$, and go to step D8.

D8. Determine the relationship between $Q_{j}$ and $\left[q_{j}, q_{j+1}\right)$ using the following sub-steps.

D8.1. If $q_{j} \leq Q_{j}<q_{j+1}$, set $\left(K_{22}^{* *}, T_{22}^{* *}\right)=\left(K_{22}^{*}, T_{22}^{*}\right)$. Calculate the retailer's annual profit $\operatorname{JTP}_{22}^{(j)}\left(m, K_{22}^{* *}, T_{22}^{* *}\right)$ using equation (3.16) and go to step D9.

D8.2. If $Q_{j} \geq q_{j+1}$, then $T_{22}^{*}$ and $K_{22}^{*}$ are not feasible solutions, set $\operatorname{JTP}_{22}^{(j)}\left(m, K_{22}^{*}, T_{22}^{*}\right)=-$ inf.

D8.3. If $Q_{j}<q_{j}$, then $T_{22}^{*}$ and $K_{22}^{*}$ are not feasible solutions. However, $\operatorname{JTP}_{22}^{(j)}\left(m, K_{22}^{*}, T_{22}^{*}\right)$ at point $T=$ $\frac{q_{j}}{D[(1-\beta) K+\beta]}$ has a maximum value. Thus, calculate $K_{22}^{\prime \prime}$ from algorithms in Appendix F. If $K_{22}^{\prime \prime}$ is feasible, go to step D8.3.1; if not, go to step D8.3.2.

D8.3.1. If $T_{w} \leq K_{22}^{\prime \prime} T_{22}^{\prime \prime} \leq M_{j}$, set $\left(K_{22}^{* *}, T_{22}^{* *}\right)=\left(K_{22}^{\prime \prime}, T_{22}^{\prime \prime}\right)$, and calculate the retailer's annual profit $\operatorname{JTP}_{22}^{(j)}\left(m, K_{22}^{* *}, T_{22}^{* *}\right)$ using equation (3.16), go to step D9. Otherwise, $T_{22}^{\prime \prime}$ and $K_{22}^{\prime \prime}$ are not feasible solutions, set $\mathrm{JTP}_{22}^{(j)}\left(m, K_{22}^{* *}, T_{22}^{* *}\right)=-$ inf, go to step D9.

D8.3.2. Let $K_{22}^{\prime \prime}=1$ and $T_{22}^{\prime \prime}=q_{j} / D$. If $T_{w} \leq K_{22}^{\prime \prime} T_{22}^{\prime \prime} \leq M_{j}$, set $\left(K_{22}^{* *}, T_{22}^{* *}\right)=\left(1, q_{j} / D\right)$, and calculate the retailer's annual profit $\operatorname{JTP}_{22}^{(j)}\left(m, K_{22}^{* *}, T_{22}^{* *}\right)$ using equation (3.16) and go to step D9. Otherwise, $T_{22}^{\prime \prime}$ and $K_{22}^{\prime \prime}$ are not feasible solutions, set $\operatorname{JTP}_{22}^{(j)}\left(m, K_{22}^{* *}, T_{22}^{* *}\right)=-$ inf, go to step D9.

D9. If $\operatorname{JTP}_{22}^{(j)}\left(m, K_{22}^{* *}, T_{22}^{* *}\right) \geq c_{j} D$, the optimal solutions $K_{22}^{* *}$ and $T_{22}^{* *}$ are found and stop. Otherwise, go to step D10.

D10. Set $\left(K_{22}^{* *}, T_{22}^{* *}\right)=(0, \infty), \operatorname{JTP}_{22}^{(j)}\left(m, K_{22}^{* *}, T_{22}^{* *}\right)=c_{j} D$.

Acknowledgements. The authors are grateful to the Editor-in-chief, Associate editors and anonymous reviewers for their valuable comments and suggestions to improve the quality of this article.

\section{REFERENCES}

[1] S.P. Aggarwal and C.K. Jaggi, Ordering policies of deteriorating items under permissible delay in payments. J. Oper. Res. Soc. 46 (1995) 658-662.

[2] H.K. Alfares and A.M. Ghaithan, Inventory and pricing model with price-dependent demand, time-varying holding cost, and quantity discounts. Comput. Ind. Eng. 94 (2016) 170-177.

[3] C.T. Chang, L.Y. Ouyang and J.T. Teng, An EOQ model for deteriorating items under supplier credits linked to ordering quantity. Appl. Math. Modell. 27 (2003) 983-996.

[4] C.T. Chang, M.C. Cheng and L.Y. Ouyang, Optimal pricing and ordering policies for non-instantaneously deteriorating items under order-size-dependent delay in payments. Appl. Math. Modell. 39 (2015) 747-763.

[5] S.C. Chen, L.E. Cárdenas-Barrón and J.T. Teng, Retailer's economic order quantity when the supplier offers conditionally permissible delay in payments link to order quantity. Int. J. Prod. Econ. 155 (2014) 284-291.

[6] Y.S. Chiu, S.C. Liu, C.L. Chiu and H.H. Chang, Mathematical modeling for determining the replenishment policy for EMQ model with rework and multiple shipments. Math. Comput. Modell. 54 (2011) 2165-2174.

[7] K.J. Chung and J.J. Liao, The optimal ordering policy of the EOQ model under trade credit depending on the ordering quantity from the DCF approach. Eur. J. Oper. Res. 196 (2009) 563-568.

[8] K.J. Chung, S.D. Lin and H.M. Srivastava, The inventory models under conditional trade credit in a supply chain system. Appl. Math. Modell. 37 (2013) 10036-10052.

[9] S.K. Goyal, Economic order quantity under conditions of permissible delay in payments. J. Oper. Res. Soc. 36 (1985) 335-338.

[10] Y.F. Huang, Economic order quantity under conditionally permissible delay in payments. Eur. J. Oper. Res. 176 (2007) 911-924.

[11] C.K. Jaggi, S. Pareek, A. Khanna and R. Sharma, Credit financing in a two-warehouse environment for deteriorating items with price-sensitive demand and fully backlogged shortages. Appl. Math. Modell. 38 (2014) 5315-5333. 
[12] A.M.M. Jamal, B.R. Sarker and S. Wang, An ordering policy for deteriorating items with allowable shortage and permissible delay in payment. J. Oper. Res. Soc. 48 (1997) 826-833.

[13] P.N. Joglekar, Comments on "A quantity discount pricing model to increase vendor profits". Manage. Sci. 34 (1988) $1391-1398$.

[14] S. Khanra, S.K. Ghosh and K.S. Chaudhuri, An EOQ model for a deteriorating item with time dependent quadratic demand under permissible delay in payment. Appl. Math. Comput. 218 (2011) 1-9.

[15] S. Khanra, B. Mandal and B. Sarkar, An inventory model with time dependent demand and shortages under trade credit policy. Econ. Modell. 35 (2013) 349-355.

[16] S. Khanra, B. Mandal and B. Sarkar, A comparative study between inventory followed by shortages and shortages followed by inventory under trade-credit policy. Int. J. Appl. Comput. Math. 1 (2015) 399-426.

[17] M. Khouja, The economic production lot size model under volume flexibility. Comput. Oper. Res. 22 (1995) 515-523.

[18] M. Khouja and A. Mehrez, Optimal inventory policy under different supplier credits. J. Manuf. Syst. 15 (1996) $334-339$.

[19] M. Lashgari, A.A. Taleizadeh and S.J. Sadjadi, Ordering policies for non-instantaneous deteriorating items under hybrid partial prepayment, partial trade credit and partial backordering. J. Oper. Res. Soc. 69 (2018) 1167-1196.

[20] L.Y. Ouyang, C.H. Ho and C.H. Su, Optimal strategy for an integrated system with variable production rate when the freight rate and trade credit are both linked to the order quantity. Int. J. Prod. Econ. 115 (2008) 151-162.

[21] L.Y. Ouyang, C.H. Ho and C.H. Su, An optimization approach for joint pricing and ordering problem in an integrated inventory system with order-size dependent trade credit. Comput. Ind. Eng. 57 (2009) 920-930.

[22] L.Y. Ouyang, J.T. Teng, S.K. Goyal and C.T. Yang, An economic order quantity model for deteriorating items with partially permissible delay in payments linked to order quantity. Eur. J. Oper. Res. 194 (2009) 418-431.

[23] L.Y. Ouyang, C.H. Ho, C.H. Su and C.T. Yang, An integrated inventory model with capacity constraint and order-size dependent trade credit. Comput. Ind. Eng. 84 (2015) 133-143.

[24] J. Ray, A nonlinear EOQ model with the effect of trade credit. Int. J. Nonlin. Sci. Num. 17 (2014) $135-144$.

[25] S.S. Sana and K.S. Chaudhuri, A deterministic EOQ model with delays in payments and price-discount offers. Eur. J. Oper. Res. 184 (2008) 509-533.

[26] B. Sarkar, An EOQ model with delay in payments and time varying deterioration rate. Math. Comput. Modell. 55 (2012) $367-377$.

[27] D. Seifert, R.W. Seifert and M. Protopappa-Sieke, A review of trade credit literature: opportunities for research in operations. Eur. J. Oper. Res. 231 (2013) 245-256.

[28] N.H. Shah and L.E. Cárdenas-Barrón, Retailer's decision for ordering and credit policies for deteriorating items when a supplier offers order-linked credit period or cash discount. Appl. Math. Comput. 259 (2015) 569-578.

[29] A.A. Shaikh, M.A.A. Khan, G.C. Panda and I. Konstantaras, Price discount facility in an EOQ model for deteriorating items with stock-dependent demand and partial backlogging. Int. Trans. Oper. Res. 26 (2019) 1365-1395.

[30] S.W. Shinn and H. Hwang, Optimal pricing and ordering policies for retailers under order-size-dependent delay in payments. Comput. Oper. Res. 30 (2003) 35-50.

[31] A.A. Taleizadeh and D.W. Pentico, An economic order quantity model with partial backordering and all-units discount. Int. J. Prod. Econ. 155 (2014) 172-184.

[32] P.S. Ting, Comments on the EOQ model for deteriorating items with conditional trade credit linked to order quantity in the supply chain management. Eur. J. Oper. Res. 246 (2015) 108-118.

[33] S. Tiwari, L.E. Cárdenas-Barrón, A.A. Shaikh and M. Goh, Retailer's optimal ordering policy for deteriorating items under order-size dependent trade credit and complete backlogging. Comput. Ind. Eng. 139 (2020) 1-12.

[34] H.L. Yang and C.T. Chang, A two-warehouse partial backlogging inventory model for deteriorating items with permissible delay in payment under inflation. Appl. Math. Modell. 37 (2013) 2717-2726.

\section{Subscribe to Open (S20)}

\section{A fair and sustainable open access model}

This journal is currently published in open access under a Subscribe-to-Open model (S2O). S2O is a transformative model that aims to move subscription journals to open access. Open access is the free, immediate, online availability of research articles combined with the rights to use these articles fully in the digital environment. We are thankful to our subscribers and sponsors for making it possible to publish this journal in open access, free of charge for authors.

\section{Please help to maintain this journal in open access!}

Check that your library subscribes to the journal, or make a personal donation to the $\mathrm{S} 2 \mathrm{O}$ programme, by contacting subscribers@edpsciences.org

More information, including a list of sponsors and a financial transparency report, available at: https://www. edpsciences.org/en/maths-s2o-programme 